\title{
Verification of a low fidelity fast simulation framework through RANS simulations
}

\author{
Martin A. Carrizales ${ }^{1}$ (i) $\cdot$ Gaétan Dussart $^{1} \cdot$ Vilius Portapas $^{1} \cdot$ Alessandro Pontillo $^{1} \cdot$ Mudassir Lone $^{1}$
}

Received: 17 April 2018 / Revised: 9 April 2019 / Accepted: 4 July 2019 / Published online: 22 July 2019

(c) The Author(s) 2019

\begin{abstract}
Verification and validation of simulation models are critical steps in engineering. This paper aims at verifying the suitability of reduced order aerodynamic models used in an aeroservoelastic framework designed to analyze the flight dynamics of flexible aircraft, known as the Cranfield Accelerated Aircraft Loads Model. This framework is designed for rapid assessment of aircraft configurations at the conceptual design stage. Therefore, it utilizes or relies on methods that are of relatively low fidelity for high computational speeds, such as modified strip theory coupled with Leishmann-Beddoes unsteady aerodynamic model. Hence, verification against higher order methods is required. Although low fidelity models are widely used for conceptual design and loads assessments, the open literature still lacks a comparison against higher fidelity models. This work focuses on steady-trimmed flight conditions and investigates the effect of aerodynamic wing deformation under such loads on aerodynamic performance. Key limitations of the reduced order models used, namely fuselage and interference effects, are discussed. The reasons for the overall agreement between the two approaches are also outlined.
\end{abstract}

Keywords Low fidelity aerodynamics $\cdot$ Aeroservoelastic framework $\cdot$ Reynolds averaged Navier-Stokes simulations

\section{Introduction}

To this day, numerous simulation tools have been developed to assess aircraft non-linear flight dynamics. These include quasi-steady aerodynamic models in the form of look-up tables $[4,41]$ or those which utilize a complex combination of empirical and advanced models [32, 33]. For low subsonic flight, panel codes based on unsteady vortex lattice methods [31] provide a means of rapid assessment of highaltitude long-endurance aircraft. On the other hand, tools designed for high Mach number cases range from corrected doublet lattice method [39] (typically used in the loads estimations process in industry) to computationally expensive unsteady computational fluid dynamics (CFD) simulations of the whole aircraft [20]. When deployed in areas of the flight envelope where these tools are valid, designers and engineers have gained significant insight on aircraft aerodynamic performance. However, the verification and validation of these reduced order models remains a significant

Martin A. Carrizales

Martin.Carrizales@cranfield.ac.uk

1 Aerospace Integration Research Centre, Cranfield University, College Road, Cranfield, UK challenge. The authors present a comparison between the aerodynamic solver of the aeroservoelastic simulation framework [34] and a CFD results. This framework, known as Cranfield Accelerated Aircraft Loads Model $\left(\mathrm{CA}^{2} \mathrm{LM}\right)$, is designed as a MATLAB/Simulink tool for rapid simulation of numerous cases [2] as well as real-time pilot-in-the-loop simulations [28] when connected to an engineering flight simulator. As for the aerodynamics, the modeling technique relies on reduced order aerodynamic methods like modified strip theory (MST) [3] and Leishman-Beddoes unsteady models [26, 27] for key aerodynamic surfaces such as the wing, horizontal, and vertical tailplanes. On the other hand, the fuselage and nacelles are modeled using empirical ESDU methodologies [9-11, 13, 16].

The authors recognize that the only true method of validation for such tools is via a comparison with data obtained from a carefully tailored flight test campaign. Given the lack of access to such data and the associated costs, the discussion here focuses on a verification with the help of steady Reynolds averaged Navier-Stokes (RANS) simulations [1]. Another challenge faced when verifying such an aeroservoelastic tool is selecting a method that considers airframe flexibility. If the verification approach only considers a comparison with high fidelity CFD coupled with high fidelity 
computational structural mechanics [37], the computational cost of such an exercise would be too high. The aim of this research work presented in this paper is to highlight the limitations of a specific modeling approach that couples MSTbased steady aerodynamic models with ESDU methods. As a result, the scope of the work discussed in this paper is limited to: (1) a comparison over a range of flight conditions and, (2) assessing the effects of wing deformation. The reader should, therefore, note that the scope of this paper is limited to the comparison of steady aerodynamic calculations; namely the RANS approach and the MST implementation. Comparisons with panel methods such as those in Refs. [18, 19, 40, 45] are considered to be beyond the scope of this paper.

This paper is structured, such that the reader is first given the details of the use case: the AX-1 large civil transport aircraft configuration. Then, a brief overview of the low fidelity method based on the classical tube and wing configuration is presented in Sect. 2. This is followed by the definition of steady CFD simulation cases in Sect. 3 that lead to a comparison with the trim solutions obtained from $\mathrm{CA}^{2} \mathrm{LM}$ in Sect. 4. In Sect. 4, the comparison is divided between undeformed and deformed airframes. Finally, Sect. 5 concludes by providing a summary of the key results.

\section{Review of $C A^{2} L M$ aerodynamics modeling}

The $C^{2}{ }^{2} L M$ framework is an aeroservoelastic simulation framework that couples structural dynamics and unsteady aerodynamics in the time domain to capture the aircraft dynamics such as structural loads. It can be used for real-time pilot-inthe-loop simulations and additional aspects such as investigating handling qualities, effect of manual controls, on flexible aircraft [29, 30] along with maneuver and gust loads [8]. The framework was developed to model a large transport aircraft known as the AX-1, as shown in Fig. 1. This framework is a MATLAB/Simulink-based tool, composed of separate blocks that carry out calculations covering the different aspects of flight mechanics. The overall architecture is shown in Fig. 2 and the reader is referred to Refs. [2, 3, 8, 28, 30, 34] for a thorough discussion of this aeroservoelastic framework.

\subsection{Modeling aerodynamic surfaces}

To obtain the aerodynamic and moments steady characteristics first the wing need to be converted into a non-crank wing, this is done by employing the method presented in the ESDU 76003 [15]. With this, the aerodynamic forces and moments block in $\mathrm{CA}^{2} \mathrm{LM}$ can calculate the wing loading, that is composed of steady aerodynamic coupled with unsteady aerodynamic models.

As for the steady aerodynamic, they are implemented by the use of MST [5, 6, 42]. MST enable the calculation of the $C_{\mathrm{L}}$, $C_{\mathrm{D}_{i}}$, and $C_{\mathrm{m}}$ along the wingspan while assuming that the wing has no discontinuities in twist. This is done by representing a series of horseshoe vortices to calculate the downwash $(w)$ at any point along the wingspan [3] as presented in Fig. 3 and represented by the following:

$$
\begin{aligned}
w(x, y) & =w_{\mathrm{t}}(x, y)+w_{\mathrm{b}}(x, y) \\
& =\frac{\mathrm{d} \Gamma}{4 \pi h_{\mathrm{t}}}\left(\cos \theta_{1}+\cos \theta_{2}\right)+\frac{\Gamma h_{\mathrm{b}} \mathrm{d} s}{4 \pi r^{3}},
\end{aligned}
$$

where $h$ is the perpendicular distance of any point $(x, y)$ to the vortex line, $\mathrm{d} \Gamma$ is the trailing vortex strength at an

Fig. 1 AX-1 use-case configuration

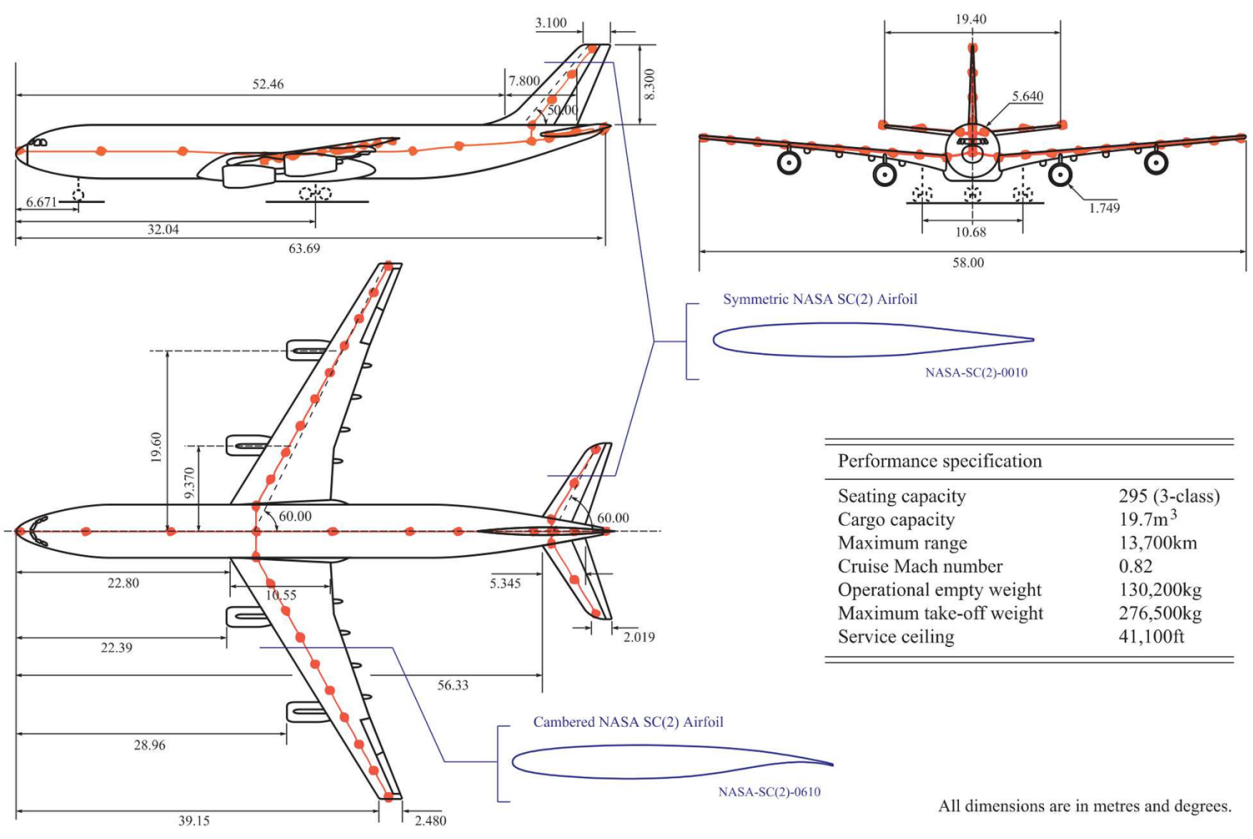


Fig. $2 \mathrm{CA}^{2} \mathrm{LM}$ framework architecture

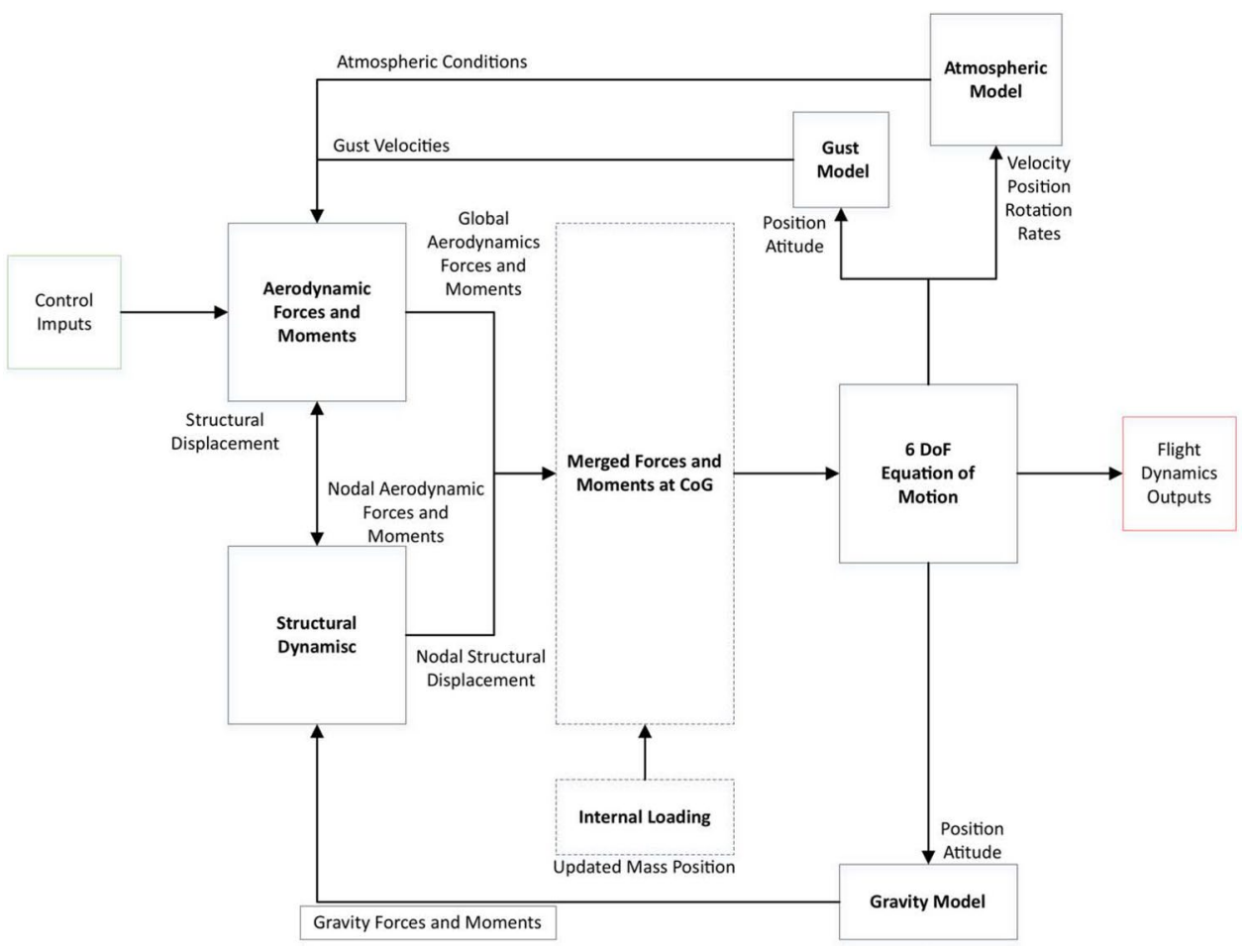

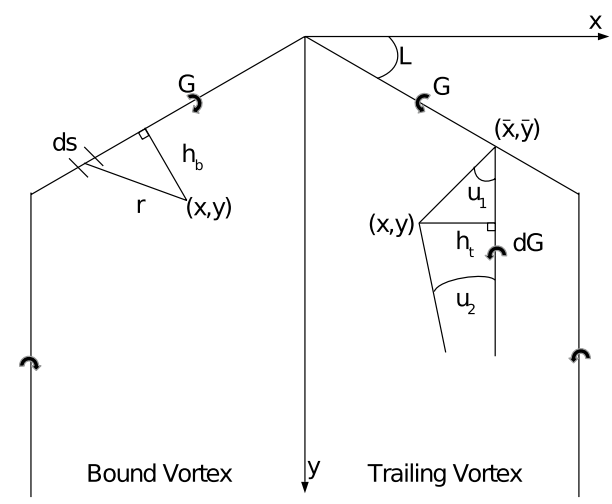

Fig. 3 Representation of horseshoe vortices along the wingspan [3]

aerodynamic station, and $\Gamma$ is the strength of the bound vortex for some small element $(\mathrm{d} s)$. By solving the downwash equation, the integrated effect of a number of trailing vortex sheets and bound vortices, while applying that the flow is tangential to the plane at the three-quarter chord line, the loading distribution may be found. As for $\Gamma$, this will depend on the local $C_{\mathrm{L}}$ (airfoil aerodynamics) in each aerodynamic station, and these coefficients are found from pre-programmed look-up tables (LUTs). The LUTs are generated by the use of XFOIL, a computational panel method [7] for subsonic flow, and VGK method for transonic flow [14].

On the other hand, using this simplified lifting-surface theory, the effects of compressibility may be accounted for using the Prandtl-Glauert correction factor:
$\beta=\sqrt{1-M^{2}}$,

where the sweep angle $(\Lambda)$ of the wing is corrected for compressibility by the following:

$\Lambda_{\beta}=\tan ^{-1}\left(\frac{\Lambda}{\beta}\right)$

as for relation between the local chord at the corresponding spanwise station $\left(b / c_{i}\right)$, this is also taken into account by the factor $\beta$. Regarding the variation of the local lift curve along the wingspan position, this is performed by a correction factor $K_{a i}$, as described by DeYoung and Harper [5]. This factor may be calculated as such:

$K_{a_{i}}=\frac{a_{i}}{2 \pi / \beta}$.

Now, the local ratio $b / c_{i}$ can be corrected by multiplying it by the correction factor $1 / K_{a_{i}}$. With this, the effects of compressibility are fully taken into account. Once that forces acting on aerodynamic surfaces are generated in the wind axis system, this needs to be transferred into the body-axis system via the application of a direction cosine matrix (DCM) with the following angles: $\theta_{i}$ the local twist angle, $\lambda_{i}$ the local sweep angle, and $\gamma_{i}$ the local dihedral angle. The various axes systems used in $\mathrm{CA}^{2} \mathrm{LM}$ are shown in Fig. 4.

The aerodynamic model also couples the wing aerodynamics with the tail aerodynamics through a wing downwash 
Fig. 4 Axes systems used in the $\mathrm{CA}^{2} \mathrm{LM}$ framework

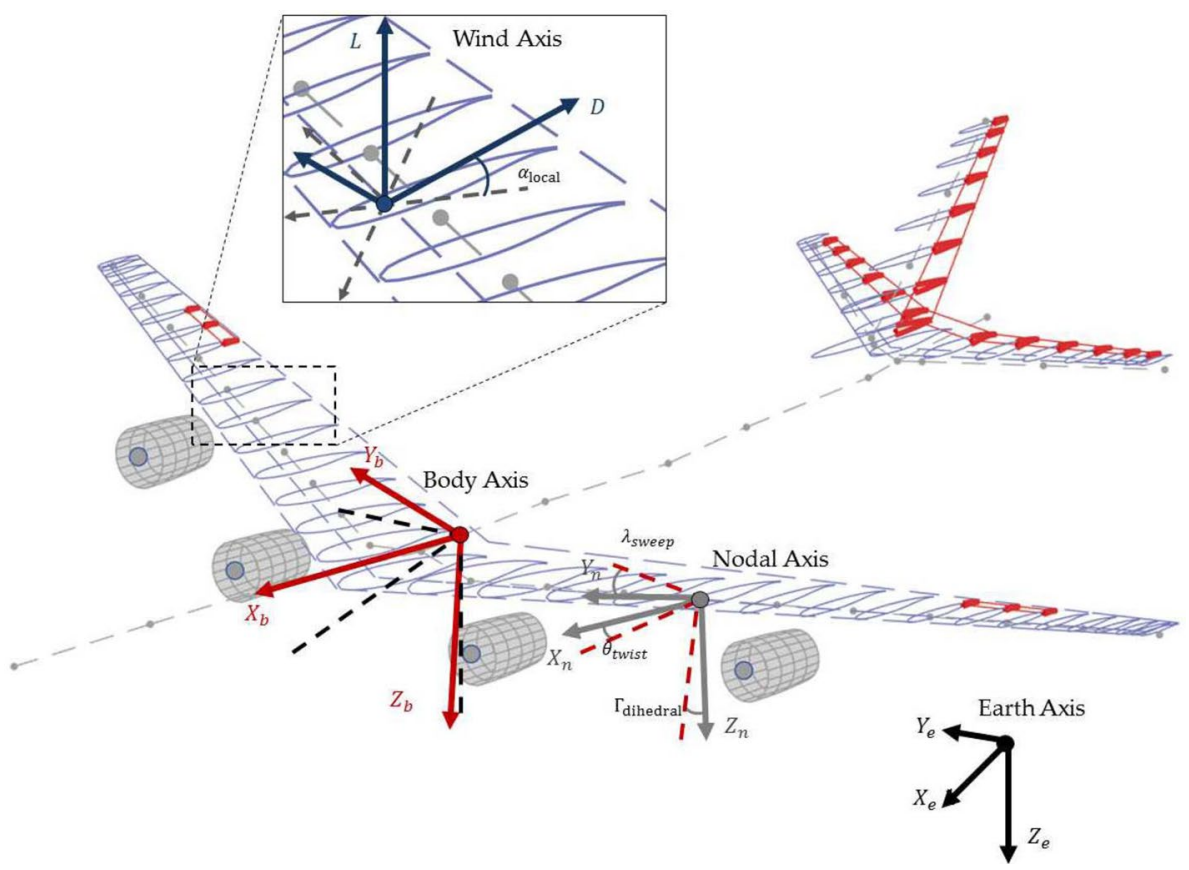

model which interacts with the tailplane. The downwash circulation strength $(\Gamma)$ is given by the following:

$\Gamma=s V \mathbf{A}_{\mathbf{n}}\left(\alpha_{\text {ind }}-\alpha_{C_{\mathrm{L}_{0}}}\right)$,

where $s$ is the span of a wing, $V$ is the velocity, $\mathbf{A}_{\mathbf{n}}$ is the influence coefficients matrix for the panels used in the MST approach, and $\alpha_{C_{\mathrm{L}}=0}$ is zero lift angle of attack. Circulation is then evaluated through a reduced order state-space model to get the indicial angle of attack for the tailplane. This coupled implementation of the MST approach and unsteady aerodynamics modeling has been found to provide a satisfactory balance between precision and computational cost [3].

\subsection{Fuselage modeling}

Due to their significant contributions to forces and moments acting on the aircraft, the fuselage and engine nacelle aerodynamics are also taken into account [3]. The normal forces in the fuselage fore-body and aft-body are presented in Fig. 5 [3].
These forces can be expressed as the summation of forebody (fb), aft-body (ab), and carry-over lift of the fuselage in the presence of the wing (bco):

$f_{\mathrm{b}}=f_{\mathrm{fb}}+f_{\mathrm{ab}}+f_{\mathrm{bco}}$,

$m_{\mathrm{b}}=m_{\mathrm{fb}}+m_{\mathrm{ab}}+m_{\mathrm{bco}}$.

Starting with the fore-body and using empirical data and slender-body theory from the ESDU 89008 [9] and 89014 [13], it is possible to approximate the fuselage as an axisymmetric body of revolution. ESDU 89014 provides the following empirical expression for the normal force coefficient in body-axes as follows:

$C_{\mathrm{N}}=C_{\mathrm{N} \alpha} \sin \alpha \cos \alpha+\frac{4}{\pi} \frac{L}{D} C_{\mathrm{PL}} C_{\mathrm{Nc}}$,

where $C_{\mathrm{N} \alpha}$ is the normal force slope obtained from ESDU 89008 [9]. The terms $C_{\mathrm{PL}}$ and $C_{\mathrm{Nc}}$ represent cross-flow effects: $C_{\mathrm{PL}}$ is a geometrical coefficient calculated via ESDU 77028 [17], while $C_{\mathrm{Nc}}$ is the cross-flow normal force coefficient and is given in the form of LUTs in ESDU 89014 as a function of Mach number and angle of attack.

Fig. 5 Normal forces acting in the fore-body and aft-body [3]

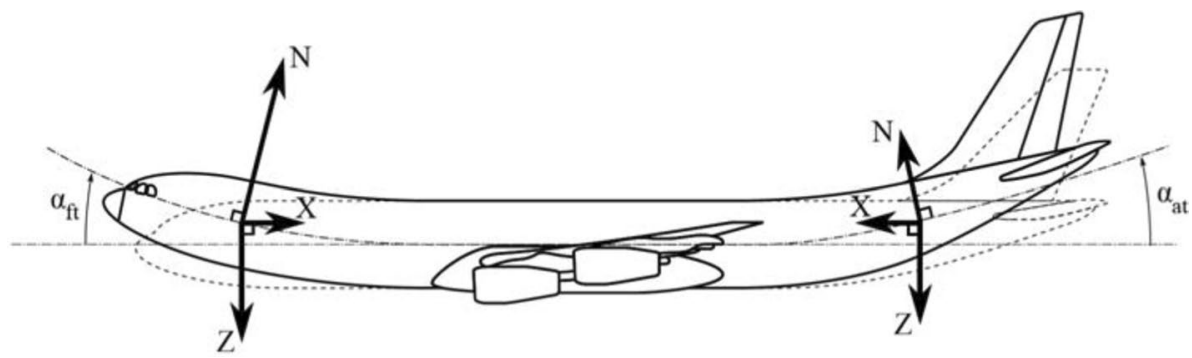


To calculate moments in the fore-body, the center of pressure needs to be calculated and is given forward of the axes origin by the following:

$X_{\mathrm{cp}}=X_{0}-\frac{\left(C_{\mathrm{m}}\right)_{0}}{C_{\mathrm{N}}} D$

where $X_{0}$ is the longitudinal location of the axes origin, $D$ is the maximum diameter of the fuselage, and the $\left(C_{\mathrm{m}}\right)_{0}$ is the pitching moment coefficient and is as follows:

$\left(C_{\mathrm{m}}\right)_{0}=\left(C_{\mathrm{m}}\right)_{0 \alpha} \sin \alpha_{\mathrm{fb}} \cos \alpha_{\mathrm{fb}}-\frac{2}{\pi}\left(\frac{L}{D}\right)^{2} C_{\mathrm{PL}} C_{\mathrm{CL}} C_{\mathrm{Nc}}$.

The first term in Eq. (10) is the value of the pitching moment coefficient at the fore-body incident angle $\left(\alpha_{\mathrm{fb}}\right)$ and the second term represents cross-flow effects on the pitching moment. As for $C_{\mathrm{CL}}$, this is given by ESDU 77028 and represents the geometric coefficients for any given cross-sectional shape.

The angle of attack of the fore-body is the sum of the elastic deformation of the fuselage and the rigid body angle of attack as presented in Fig. 6 and given by the following:

$\alpha_{\mathrm{fb}}=\alpha+\alpha_{\mathrm{ft}}$.

The forces and moment contribution from the fore-body in the body-axes can now be calculated as follows:

$f_{\mathrm{fb}}=q S_{\mathrm{b}}\left[\begin{array}{c}0 \\ 0 \\ -C_{\mathrm{N}}\end{array}\right]$,

$m_{\mathrm{fb}}=q S_{\mathrm{b}}\left[\begin{array}{c}0 \\ -C_{\mathrm{N}} X_{\mathrm{ep}} \\ 0\end{array}\right]$,

where $S_{\mathrm{b}}$ is the reference area of the fuselage given by $\pi D^{2} / 4$.

The aft-body contributions can be estimated from slenderbody theory, again approximated as an axisymmetric body and the change in normal force is given by the following:

$\Delta C_{\mathrm{N}}=\Delta C_{\mathrm{N} \alpha} \sin \alpha \cos \alpha\left(1-\sin ^{0.6} \alpha\right)+\Delta C_{\mathrm{D}_{\mathrm{c}}} \sin ^{2} \alpha$,

$\Delta C_{\mathrm{N} \alpha}$ represents the inviscid contribution calculated according to slender-body theory and $\Delta C_{\mathrm{D}_{\mathrm{c}}}$ represents the viscous cross-flow contribution. The angle of attack for the aft-body, as presented in Fig. 6, is given by the following:

$\alpha_{\mathrm{ab}}=\alpha-\alpha_{\mathrm{at}}$

The center of pressure due to change in normal force is approximated in the aft-body as follows:

$X_{\mathrm{ep}}^{\prime}=X_{0}-0.5 l_{\mathrm{a}}$,

where $l_{\mathrm{a}}$ is the length of the aft-body boat-tail.

Now, with this, the forces and moments about the bodyaxes can be calculated as follows:

$f_{\mathrm{ab}}=q S_{\mathrm{b}}\left[\begin{array}{c}0 \\ 0 \\ -\Delta C_{\mathrm{N}}\end{array}\right]$,

$m_{\mathrm{ab}}=q S_{\mathrm{b}}\left[\begin{array}{c}0 \\ -\Delta C_{\mathrm{N}} X_{\mathrm{ep}}^{\prime} \\ 0\end{array}\right]$.

The fuselage drag profile is estimated assuming it to be an axisymmetric body using ESDU 77028:

$C_{\mathrm{D}}=\left(\frac{C_{\mathrm{v}}^{2 / 3}}{2(2 \pi L / D)^{1 / 3} C_{\mathrm{s}}}\right) C_{\mathrm{D}}^{*}$,

where $C_{\mathrm{D}}^{*}$ is the body profile drag coefficient based on $2 / 3$ of volume and the geometric coefficients $C_{\mathrm{v}}$ and $C_{\mathrm{s}}$ are calculated from the ESDU 77028 by the following equations:

$C_{\mathrm{v}}=\frac{4 V}{\pi D^{2} L}$,

$C_{\mathrm{s}}=\frac{S}{\pi D L}$.

Now, the forces acting on the fuselage, assuming that the drag profile acts axially about the axis origin, are given as follows:

$f_{\mathrm{b}}=q S_{\mathrm{b}}\left[\begin{array}{c}C_{\mathrm{D}} \\ 0 \\ 0\end{array}\right]$.
Fig. 6 Angle of attack of the fore-body and aft-body of the fuselage [3]

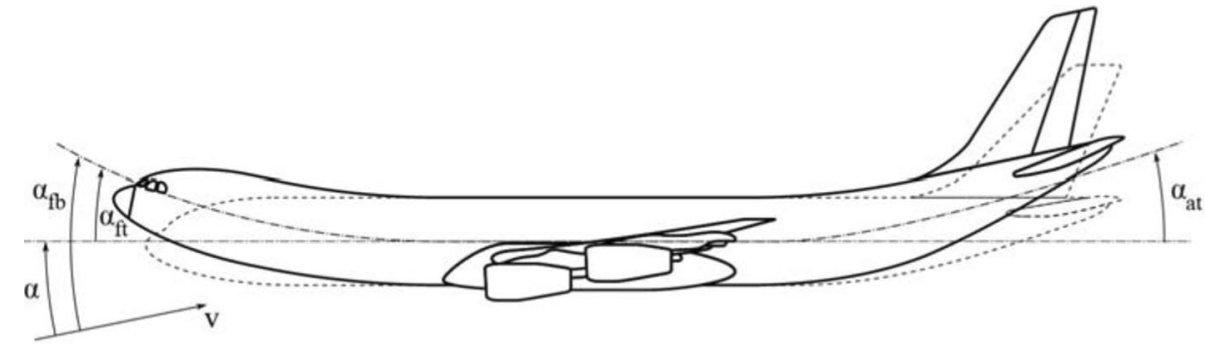


As for the nacelles, this are modeled in $\mathrm{CA}^{2} \mathrm{LM}$ as annular aerofoils using a correction for the upwash of the wing as presented in ESDU 70012 [16].

\subsection{Aerodynamic interactions}

The interaction between all the different parts of the aircraft is an important part of understanding the overall aerodynamic characteristics. The $\mathrm{CA}^{2} \mathrm{LM}$ framework takes into account the following interactions:

1. Wing-tailplane through the downwash model.

2. Wing-fuselage according to the ESDU 94009 [11].

Regarding the wing-fuselage interaction the lift is obtained in the outboard $\left(\left(C_{\ell}\right)_{\omega(f)}\right)$ and inboard $\left(\left(C_{\ell}\right)_{f(\omega)}\right)$ stations as follows:

$\left(C_{\ell}\right)_{\omega(f)}=K_{\omega(f)}\left(C_{\ell_{i}}\right)$,

$\left(C_{\ell}\right)_{f(\omega)}=K_{f(\omega)}\left(C_{\ell_{i}}\right)$,

where $K_{\omega(f)}$ and $K_{f(\omega)}$ are two factors obtained from the ESDU 91007 [12]. These effectively modify the wing lift and drag contributions calculated at various aerodynamic stations if these are within the interference distance. However, the interaction between the vertical stabilizer and the fuselage is not modeled.

\section{Definition of RANS simulations}

Analyzing the entire aircraft using CFD not only allows the calculation of overall aerodynamic forces and moments, but also gives an insight into the interactions between the various airframe components: like the impact of the fuselage on wing aerodynamics. Hence, the viscous effects are modeled using a Reynolds averaged Navier Stokes (RANS) solver. However, to carry out such simulations, flight conditions of interest must be clearly specified. These are defined based on

Table 1 Analysis cases for underformed and deformed configurations

\begin{tabular}{llrlll}
\hline FC & \multicolumn{1}{l}{ Cruise } & & & & \\
\cline { 2 - 5 } & Airframe & \multicolumn{1}{l}{ FL } & $M$ & TAS $(\mathrm{m} / \mathrm{s})$ & Reynolds no. \\
\hline 1 & $U$ & 0 & 0.5 & 169 & $8.397 \mathrm{e}^{7}$ \\
2 & $U$ & 50 & 0.55 & 182 & $8.041 \mathrm{e}^{7}$ \\
3 & $U$ & 100 & 0.59 & 195 & $7.594 \mathrm{e}^{7}$ \\
4 & $U$ & 150 & 0.65 & 210 & $7.171 \mathrm{e}^{7}$ \\
5 & $U$ & 200 & 0.71 & 225 & $6.705 \mathrm{e}^{7}$ \\
6 & $U$ & 150 & 0.58 & 190 & $6.488 \mathrm{e}^{7}$ \\
7 & $D$ & 150 & 0.58 & 190 & $6.488 \mathrm{e}^{7}$ \\
\hline
\end{tabular}

the operating envelope of the AX-1 model and the conditions over which methods within the $\mathrm{CA}^{2} \mathrm{LM}$ framework are valid. Since the $\mathrm{CA}^{2} \mathrm{LM}$ framework is capable of simulating rigid and elastic airframes, CFD simulations for two configurations were carried out:

1. Undeformed $(U)$ airframe over a range of flight conditions to obtain lift and drag polars (cases 1-6).

2. Deformed $(D)$ airframe in flight shape at one flight condition to study the effects of airframe flexibility (case 7).

The flight conditions for performing the CFD simulations are summarized in Table 1 and Fig. 7.

The value of $\alpha$ varies from $-3^{\circ}$ to $3^{\circ}$ for cases $1-5$, and from $-2^{\circ}$ to $4^{\circ}$ for cases 6 and 7 . The AX-1 aircraft geometry used for RANS simulations was developed based on data used in the $\mathrm{CA}^{2} \mathrm{LM}$ framework [3]. Both geometries were developed using a computer-aided design software (CATIA), and are shown in Fig. 8.

After defining the simulation cases and developing the aircraft models, a control volume is selected, so that a suitable mesh can be generated for CFD. The geometry of the control volume needs to be defined carefully because of the impact on the mesh generation process and the consequent results. For this study, the C-type control volume was chosen (see Fig. 9), because it was convenience for the meshing process. The size is defined in terms of the fuselage length $(L)$. The inlet radius is equal to $5 L$ and aft of the aircraft the size is of $10 \mathrm{~L}$. To capture the aerodynamic features affecting

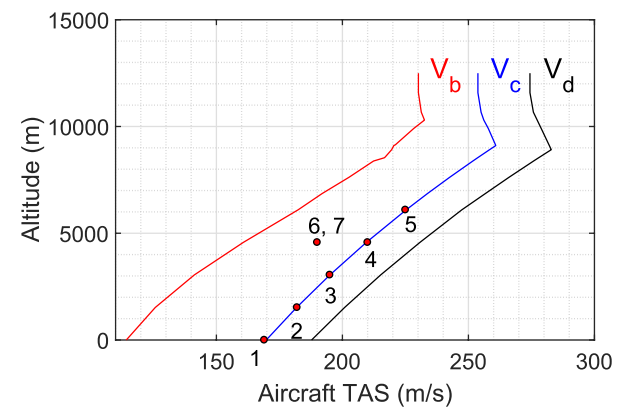

Fig. 7 Mission profile selected points

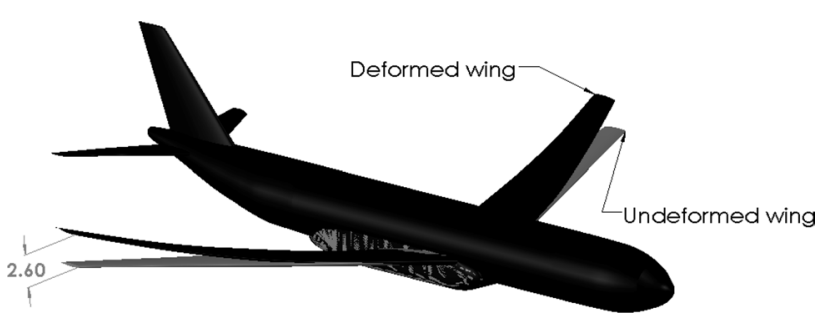

Fig. 8 Models of undeformed (cases 1-6) and deformed (case 7) cases 


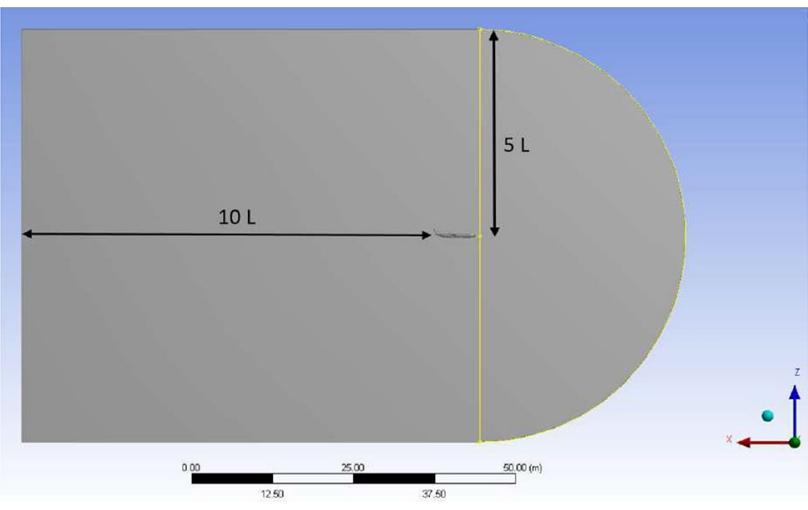

Fig. 9 C-type control volume of the generated mesh

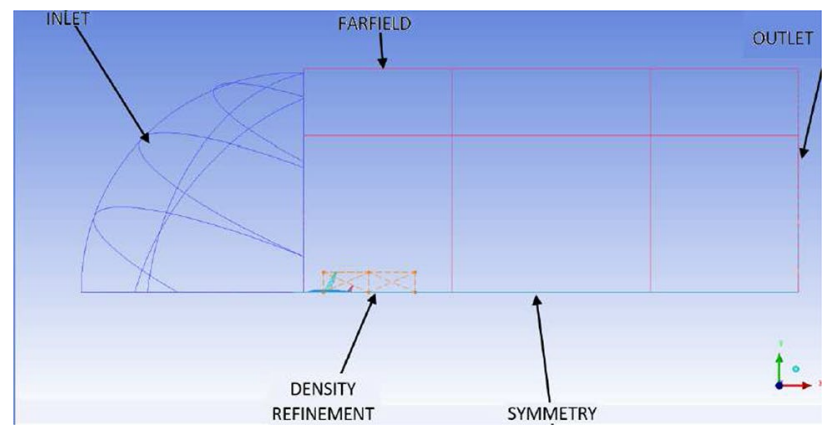

Fig. 10 Density refinement zone around the aircraft model

lift and drag in a more precise way, a refinement zone was created around the model, as shown in Fig. 10.

The next step before starting the CFD analysis is to create the mesh. Therefore, a baseline mesh was defined and a grid convergence study was carried out. The parameters of the baseline mesh are given in Table 2. This base mesh contains 17.5 million elements with a mean quality value of 0.82 and a skewness value of 0.15 for only $0.003 \%$ of the elements, ensuring that the results will be accurate and that the simulation will not fail. The baseline mesh is presented in Fig. 11.

Once the baseline mesh was defined, a grid convergence study was carried out to select the adequate meshing parameters: choosing the suitable trade-off between quality and computational cost of the simulation. The new meshes were created using the parameter in Table 2 with an increase or decrease ratio of 1.5. This study was carried out with four meshes with the number of elements ranging from around 8-26 million. And, as for the turbulence model to be implemented, several options are available. The most commonly used in the aerodynamic analysis are as follows:

- Spalart-Allmaras 1-equation model.

- $k-\epsilon$ and $k-\omega 2$-equation model.

- SST transition 4-equation model.

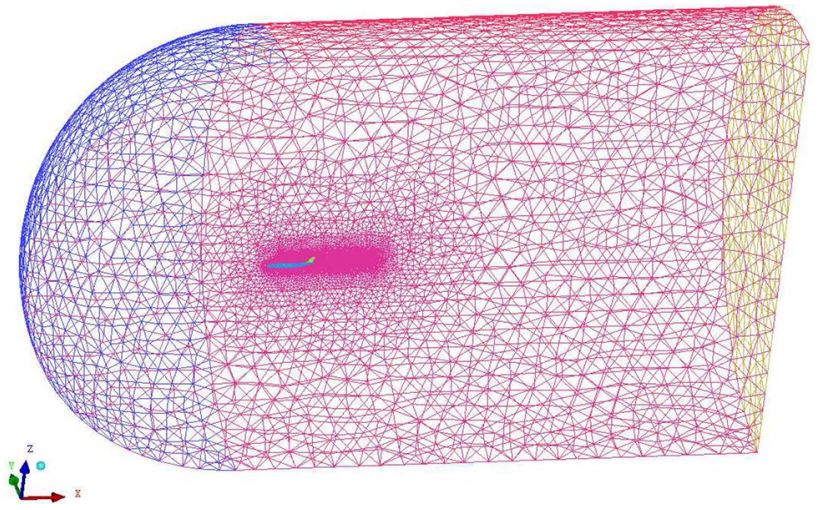

Fig. 11 Baseline mesh for AX-1 aircraft

Table 2 Baseline mesh parameters

\begin{tabular}{ll}
\hline Mesh settings & Values \\
\hline Surface maximum size $(\mathrm{mm})$ & 65 \\
Edge maximum size $(\mathrm{mm})$ & 30 \\
Density refinement size $(\mathrm{m})$ & 1.5 \\
Density refinement ratio & 1.25 \\
Global element seed size $(\mathrm{mm})$ & 32768 \\
\hline
\end{tabular}

The differences lay in the number of extra terms or equations added to Navier-Stokes equations. Starting with the model known as SST transition model, this is a four-equation model that combines the shear stress transport (SST) $k-\omega$ equations plus one equation for intermittency $(\gamma)$ and another for the transition sources criteria $\left(\operatorname{Re}_{\theta}\right)$ [24]. As for the twoequation models, the main ones are the $k-\epsilon$ and $k-\omega$, the first one is the simplest model of turbulence in which the solution to two separate equations allows the turbulence velocity and length scales to be independently determined by the use of the transport equation for the turbulence kinetic energy $(k)$ and its dissipation rate $(\epsilon)$ [25]. The second model $k-\omega$ is different due to modifications intended to capture low Reynolds numbers effects such as compressibility and shear flow spreading by the use of the transport equation for the turbulence kinetic energy $(k)$ and the specific dissipation rate $(\omega)[23,43,44]$. The Spalart-Allmaras model, on the other hand, uses only one equation to solve the kinematic eddy viscosity by solving the viscosity affected region of the boundary layer [38]. Increasing the number of equations allows the viscous effects and turbulence models to be predicted and solved more accurately, but this has the drawback of higher computational cost as presented in Fig. 12.

For this study, a two-equation model, more specifically, the realizable $k-\epsilon$ with a standard wall function was selected, because it gives a suitable trade-off between computational cost and accuracy. A total of 21 simulations 


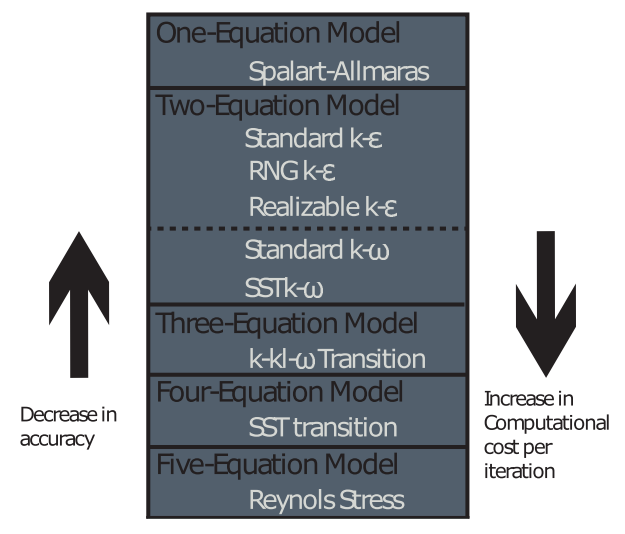

Fig. 12 Trade-off between computational cost and accuracy

were run using the Cranfield University HPC system, for which each simulation consisted of 1500 iterations.

After performing all the analyses, the meshes presented a mean $y^{+}$(non-dimensional unit that measures the wall distance times the shear velocity divided by the kinematic viscosity [22]) value varying between 70 and 73 , indicating that the results will follow the log law $[35,36]$. The actual comparison between all the meshes was done by observing changes in both the lift $\left(C_{\mathrm{L}}\right)$ and $\operatorname{drag}\left(C_{\mathrm{D}}\right)$ as the mesh was further refined. Figure 13 shows how these coefficients vary with respect to computational cost.

The grid convergence study shows that as the mesh density decreases, the computational time decreases, but the precision of $C_{\mathrm{L}}$ and $C_{\mathrm{D}}$ results start to diverge. On the other hand as the mesh density increases the computational time and precision of $C_{\mathrm{L}}$ and $C_{\mathrm{D}}$ results increases accordingly. With this in mind and given that the difference in computational time between the extra fine and the fine mesh is of $136 \%$, it was decided to keep using the parameters of the fine mesh given in Table 2 for all other meshes.

\section{Comparison between CA ${ }^{2}$ LM and RANS}

In this section, a comparison between the aerodynamic outputs from the $\mathrm{CA}^{2} \mathrm{LM}$ framework and those obtained from the RANS simulations is presented. Moreover, this comparison is also carried out for contributions from the various airframe components. It should be noted that this study is limited to linear aerodynamics and only the lift and drag coefficients are compared. The lift coefficient $\left(C_{\mathrm{L}}\right)$ is compared by considering the lift curve slope $\left(C_{\mathrm{L}_{\alpha}}\right)$; this was obtained by making a linear regression due that the data are very linear. Another parameter taken into account for the $C_{\mathrm{L}}$ comparison is the lift coefficient at zero angle of attack $\left(C_{\mathrm{L}_{\alpha=0}}\right)$. The relative differences $\left(\Delta_{\mathrm{L}}\right)$ for both parameters are calculated as follows:

$\Delta_{\mathrm{L}}=\frac{\hat{C}_{[]}-C_{[]}}{C_{[]}}$,

where $\hat{C}$ is the RANS data and $C$ is the data from $C^{2}{ }^{2} \mathrm{LM}$.

Regarding the drag coefficient, starting form the traditional model:

$C_{\mathrm{D}}=C_{\mathrm{D}_{0}}+C_{\mathrm{D}_{\mathrm{i}}}$

where in practice $C_{\mathrm{D}_{i}}$ is approximately a function of $C_{\mathrm{L}}^{2}$ and conventionally the total drag coefficient is written as follows:

$C_{\mathrm{D}}=C_{\mathrm{D}_{0}}+k C_{\mathrm{L}}^{2}$

where $k$ represents the lift-induced drag constant and the simple way to obtained depends on the aspect ratio (AR) and the Oswald wing efficiency factor described as follows:

$k=\frac{1}{\pi \cdot e \cdot \mathrm{AR}}$.

Hence, the difference in drag coefficient $\left(\Delta_{\mathrm{D}}\right)$ is done in the same way that for $\Delta_{\mathrm{L}}$ by comparing two values. However, having that the $C_{\mathrm{D}}$ depends on the parabolic model, it was decided to use instead of $C_{\mathrm{D}_{0}}$ that is constant. To obtain
Fig. 13 Comparison of $C_{\mathrm{L}}$ and $C_{\mathrm{D}}$ for different mesh fineness

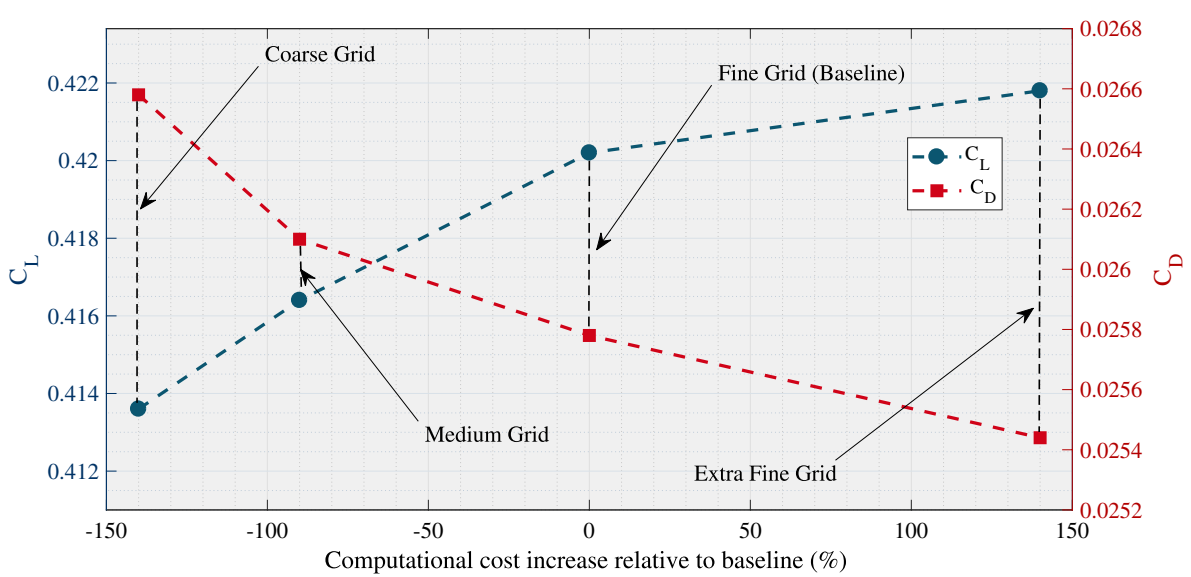


the $C_{\mathrm{D}_{0}}$, the values of $C_{\mathrm{D}}$ and $C_{\mathrm{L}}$ will be obtained from the RANS analysis and the data from $\mathrm{CA}^{2} \mathrm{LM}$ at $0^{\circ}$ of the angle of attack. As for the $k$ instead of using Eq. (28), a more exact formulation described by Howe [21] for subsonic aircraft with moderate-to-high AR is employed: are studied. It is, therefore, possible to observe the contributions of $C_{\mathrm{L}}$ and $C_{\mathrm{D}}$ for the different components and identify areas where corrections are necessary.

$k=\left[\frac{\left(1+0.12 M^{6}\right)}{\pi \mathrm{AR}}\left(1+\frac{\left(0.142+f(\lambda) \mathrm{AR}(10 t / c)^{0.33}\right)}{\left(\cos \Lambda_{1 / 4}\right)^{2}}+\frac{0.1\left(3 N_{e}+1\right)}{(4+\mathrm{AR})^{0.8}}\right)\right]$,

where $N_{\mathrm{e}}$ is the number of engines employed, $t / c$ is the airfoil thickness, and $f(\lambda)$ is a taper ratio function given by the following:

$f(\lambda)=0.005\left(1+1.5(\lambda-0.6)^{2}\right)$.

Taking into account that for this study the model does not have engines, that $\lambda$ is equal to 0.235 and that the airfoil employed is the NASA-SC(2)0610 with a $t / c$ of 0.1 . Table 3 presents the different value of $k$ according to the different cases, as showed in Table 1.

As can be see in Table 3, the value of $k$ is really close between all cases, because of this, an average value of 0.04349 will be employed to obtain $C_{\mathrm{D}_{0}}$.

In the following subsections, the comparisons for $C_{\mathrm{L}}$ and $C_{\mathrm{D}}$ for cases 1-5 are presented. These focus on the undeformed airframe and aim to verify the outputs from $C^{2} A^{2} \mathrm{LM}$ over a range of flight conditions. First, overall airframe aerodynamics are considered before separate contributions from each subcomponent (wing, fuselage, HTP, and VTP)

Table 3 Lift-induced drag constant $(k)$ for cases $1-5$

\begin{tabular}{lll}
\hline Case & $M$ & $k$ \\
\hline 1 & 0.5 & 0.043273 \\
2 & 0.55 & 0.043336 \\
3 & 0.59 & 0.043411 \\
4 & 0.65 & 0.043583 \\
5 & 0.71 & 0.043856 \\
\hline
\end{tabular}

\subsection{Lift and drag comparison for the entire aircraft}

The overall aircraft lift coefficient obtained using $\mathrm{CA}^{2} \mathrm{LM}$ compares well with the results from the RANS simulations. The largest difference is observed for case 2 where $C_{\mathrm{L}_{\alpha}}$ and $C_{\mathrm{L}_{0}}$ differ by around $8 \%$. Figure $14 \mathrm{a}$ and Table 4 show that the steady aerodynamics model in $\mathrm{CA}^{2} \mathrm{LM}$ is consistently underestimating the overall lift.

With regards to the drag coefficient, the differences range between 12 and $18 \%$ where the most significant difference is observed for case 2 . The overall trend is shown in Table 4 and Fig. 14b. It can be stated that the drag modeling method in $\mathrm{CA}^{2} \mathrm{LM}$ leads to significant drag overestimation and, therefore, tends to provide more conservative results.

\subsection{Fuselage lift and drag coefficient comparison}

The fuselage presents the largest difference due to the limitations of the empirical methods implemented in $\mathrm{CA}^{2} \mathrm{LM}$. Contribution to lift coefficient differs between $270 \%$ to $287 \%$ (see Table 5). In Fig. 15a, cases 2 and 4 are presented, which represent the extreme difference. Based on these trends, it can be stated that $\mathrm{CA}^{2} \mathrm{LM}$ strongly underestimates the fuselage lift compared to RANS results.

On the other hand, fuselage drag calculated by $\mathrm{CA}^{2} \mathrm{LM}$ depends entirely on the ESDU method. Table 5 shows that the difference varies between 111 and 124\%, implying that $\mathrm{CA}^{2} \mathrm{LM}$ underestimates the drag generated by the fuselage
Fig. 14 Results comparison between RANS and $\mathrm{CA}^{2} \mathrm{LM}$

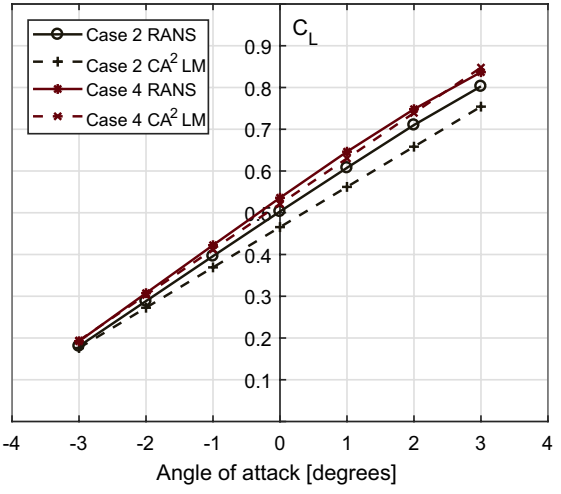

(a)

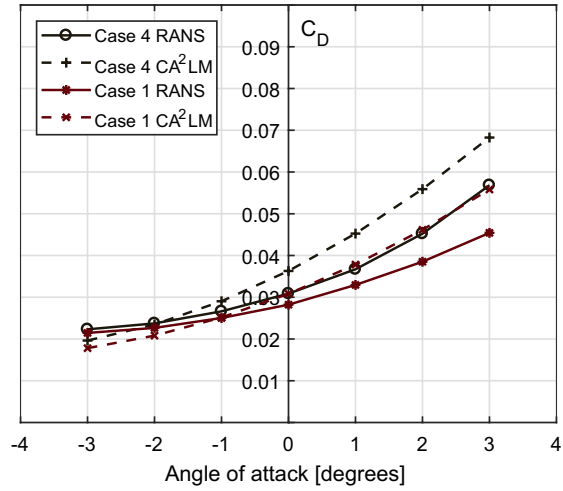

(b) 
Table 4 Aircraft lift and drag coefficient comparison for cases $1-5$

Fig. 15 Fuselage result comparison between RANS and $\mathrm{CA}^{2} \mathrm{LM}$

\begin{tabular}{|c|c|c|c|c|c|c|c|c|}
\hline \multirow[t]{2}{*}{ Case } & & \multicolumn{3}{|l|}{ Lift } & & \multicolumn{3}{|l|}{ Drag } \\
\hline & & RANS & $\mathrm{CA}^{2} \mathrm{LM}$ & $\Delta_{\mathrm{L}}(\%)$ & & RANS & $\mathrm{CA}^{2} \mathrm{LM}$ & $\Delta_{\mathrm{D}}(\%)$ \\
\hline \multirow[t]{2}{*}{1} & $C_{\mathrm{L}_{\alpha}}$ & 0.1021 & 0.0961 & 6.2669 & $C_{\mathrm{D}_{\alpha=0}}$ & 0.0282 & 0.0308 & -8.4628 \\
\hline & $C_{\mathrm{L}_{\alpha=0}}$ & 0.4902 & 0.4653 & 5.3571 & $C_{\mathrm{D}_{0}}$ & 0.0178 & 0.0214 & -17.022 \\
\hline \multirow[t]{2}{*}{2} & $C_{\mathrm{L}_{\alpha}}$ & 0.1037 & 0.0964 & 7.6334 & $C_{\mathrm{D}_{\alpha=0}}$ & 0.0287 & 0.0312 & -7.9035 \\
\hline & $C_{\mathrm{L}_{\alpha=0}}$ & 0.5031 & 0.4656 & 8.0461 & $C_{\mathrm{D}_{0}}$ & 0.0177 & 0.0214 & -17.2044 \\
\hline \multirow[t]{2}{*}{3} & $C_{\mathrm{L}_{\alpha}}$ & 0.1043 & 0.1034 & 0.8696 & $C_{\mathrm{D}_{\alpha=0}}$ & 0.0296 & 0.0339 & -12.8222 \\
\hline & $C_{\mathrm{L}_{\alpha=0}}$ & 0.5148 & 0.498 & 3.373 & $C_{\mathrm{D}_{0}}$ & 0.0181 & 0.0214 & -15.6632 \\
\hline \multirow[t]{2}{*}{4} & $C_{\mathrm{L}_{\alpha}}$ & 0.1074 & 0.1089 & -1.400 & $C_{\mathrm{D}_{\alpha=0}}$ & 0.0309 & 0.0363 & -14.9546 \\
\hline & $C_{\mathrm{L}_{\alpha=0}}$ & 0.5358 & 0.5212 & 2.8038 & $C_{\mathrm{D}_{0}}$ & 0.0184 & 0.0214 & -14.1514 \\
\hline \multirow[t]{2}{*}{5} & $C_{\mathrm{L}_{\alpha}}$ & 0.1167 & 0.1141 & 2.2892 & $C_{\mathrm{D}_{\alpha=0}}$ & 0.0329 & 0.0381 & -13.6688 \\
\hline & $C_{\mathrm{L}_{\alpha=0}}$ & 0.5681 & 0.5329 & 6.5938 & $C_{\mathrm{D}_{0}}$ & 0.0188 & 0.0214 & -12.0645 \\
\hline
\end{tabular}

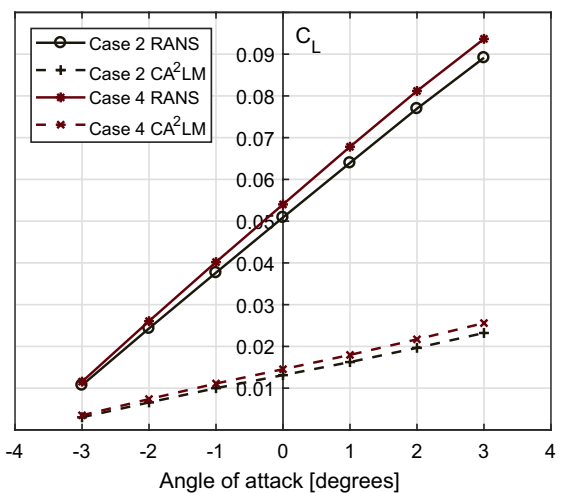

(a)

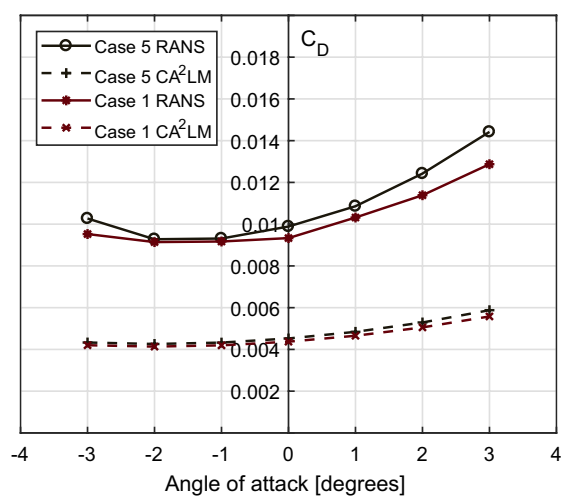

(b)
Table 5 Fuselage lift and drag coefficient comparison for cases $1-5$

\begin{tabular}{|c|c|c|c|c|c|c|c|c|}
\hline \multirow[t]{2}{*}{ Case } & & \multicolumn{3}{|l|}{ Lift } & & \multicolumn{3}{|l|}{ Drag } \\
\hline & & RANS & $\mathrm{CA}^{2} \mathrm{LM}$ & $\Delta_{\mathrm{L}}(\%)$ & & RANS & $\mathrm{CA}^{2} \mathrm{LM}$ & $\Delta_{\mathrm{D}}(\%)$ \\
\hline \multirow[t]{2}{*}{1} & $C_{\mathrm{L}_{\alpha}}$ & 0.0128 & 0.0034 & 275.069 & $C_{\mathrm{D}_{\alpha=0}}$ & 0.0093 & 0.0044 & 113.5179 \\
\hline & $C_{\mathrm{L}_{\alpha=0}}$ & 0.0498 & 0.0132 & 278.6367 & $C_{\mathrm{D}_{0}}$ & 0.0092 & 0.0044 & 111.4108 \\
\hline \multirow[t]{2}{*}{2} & $C_{\mathrm{L}_{\alpha}}$ & 0.0131 & 0.0034 & 288.3921 & $C_{\mathrm{D}_{\alpha=0}}$ & 0.0093 & 0.0043 & 118.0027 \\
\hline & $C_{\mathrm{L}_{\alpha=0}}$ & 0.0509 & 0.0131 & 287.8623 & $C_{\mathrm{D}_{0}}$ & 0.0092 & 0.0044 & 111.3551 \\
\hline \multirow[t]{2}{*}{3} & $C_{\mathrm{L}_{\alpha}}$ & 0.0133 & 0.0035 & 275.3027 & $C_{\mathrm{D}_{\alpha=0}}$ & 0.0095 & 0.0045 & 112.692 \\
\hline & $C_{\mathrm{L}_{\alpha=0}}$ & 0.052 & 0.014 & 272.1238 & $C_{\mathrm{D}_{0}}$ & 0.0094 & 0.0044 & 114.737 \\
\hline \multirow[t]{2}{*}{4} & $C_{\mathrm{L}_{\alpha}}$ & 0.0137 & 0.0037 & 271.6477 & $C_{\mathrm{D}_{\alpha=0}}$ & 0.0097 & 0.0045 & 115.1177 \\
\hline & $C_{\mathrm{L}_{\alpha=0}}$ & 0.054 & 0.0145 & 271.4644 & $C_{\mathrm{D}_{0}}$ & 0.0096 & 0.0044 & 119.7395 \\
\hline \multirow[t]{2}{*}{5} & $C_{\mathrm{L}_{\alpha}}$ & 0.0144 & 0.0038 & 278.5398 & $C_{\mathrm{D}_{\alpha=0}}$ & 0.0099 & 0.0045 & 118.5329 \\
\hline & $C_{\mathrm{L}_{\alpha=0}}$ & 0.0571 & 0.0148 & 287.1643 & $C_{\mathrm{D}_{0}}$ & 0.0097 & 0.0044 & 123.3479 \\
\hline
\end{tabular}

by a factor of approximately 2 . The causes of this discrepancy lye in the assumptions in the ESDU method, and that $\mathrm{CA}^{2} \mathrm{LM}$ does not take into account skin friction drag along the fuselage length nor the drag produced by the interaction of the fuselage and other components. This is more clearly observable in Fig. $15 \mathrm{~b}$ where case 5 presents the greatest difference and case 1 the lowest. It should be noted that the drag difference between the cases is negligible (cases 5 and 1 differ by approximately $5 \%$ ).

\subsection{Wing lift and drag coefficient comparison}

Aerodynamics associated with the wing dominate the aircraft's aerodynamics and consequently its flight dynamics. Table 6 presents the comparison between RANS and $\mathrm{CA}^{2} \mathrm{LM}$. It shows that for all cases, the lift coefficient difference between the two solvers is below $10 \%$, indicating that the steady aerodynamics model in $\mathrm{CA}^{2} \mathrm{LM}$ is in good 
agreement with the RANS results. Figure 16a shows the extreme cases, namely cases 2 and 5 .

While the drag coefficient shows that at $-3^{\circ}$ of $\alpha$, the $C_{\mathrm{D}}$ value is practically the same for both RANS and $\mathrm{CA}^{2} \mathrm{LM}$ (Fig. 16b), the differences start to increase, primarily due to the simplified aerodynamic modeling in $\mathrm{CA}^{2} \mathrm{LM}$. It operates under the assumption of inviscid flow, and by doing so, contributions due to viscous effects are not calculated. The results from all other cases are presented in Table 6.

\subsection{Empennage analysis}

Considering the HTP contributions shown in Fig. 17a, it is evident that both $\mathrm{CA}^{2} \mathrm{LM}$ and RANS simulations produce downforce within the angle of attack range considered here, and have relatively small values of $C_{\mathrm{L}_{\alpha}}$. Differences between $44 \%$ and $50 \%$ are observed for the two methods (as presented in Table 7).

Now, looking into the drag coefficient comparison, Fig. $17 \mathrm{~b}$ presents the drag polars for cases 1 and 5. It should
Fig. 16 Wing result comparison between RANS and $\mathrm{CA}^{2} \mathrm{LM}$
Table 6 Wing lift and drag coefficient comparison for cases $1-5$

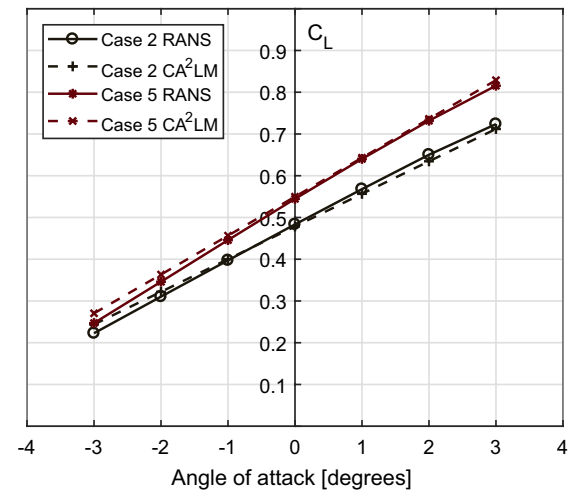

(a)

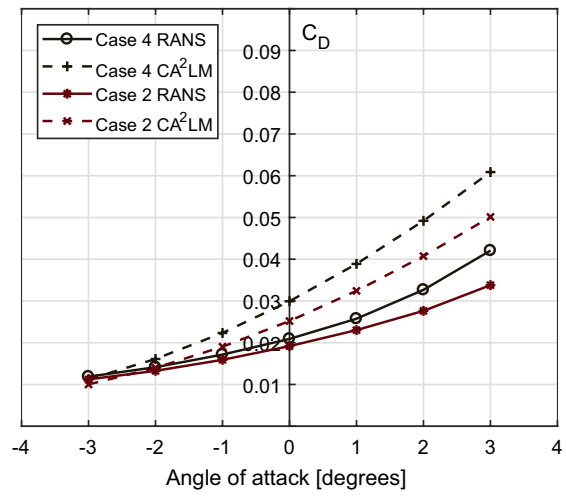

(b)

\begin{tabular}{|c|c|c|c|c|c|c|c|c|}
\hline \multirow[t]{2}{*}{ Case } & & \multicolumn{3}{|l|}{ Lift } & & \multicolumn{3}{|l|}{ Drag } \\
\hline & & RANS & $\mathrm{CA}^{2} \mathrm{LM}$ & $\Delta_{\mathrm{L}}(\%)$ & & RANS & $\mathrm{CA}^{2} \mathrm{LM}$ & $\Delta_{\mathrm{D}}(\%)$ \\
\hline \multirow[t]{2}{*}{1} & $C_{\mathrm{L}_{\alpha}}$ & 0.0822 & 0.0776 & 5.9211 & $C_{\mathrm{D}_{\alpha=0}}$ & 0.0186 & 0.0247 & -24.5944 \\
\hline & $C_{\mathrm{L}_{\alpha=0}}$ & 0.4710 & 0.4786 & -1.5949 & $C_{\mathrm{D}_{0}}$ & 0.009 & 0.0147 & -39.0953 \\
\hline \multirow[t]{2}{*}{2} & $C_{\mathrm{L}_{\alpha}}$ & 0.0835 & 0.078 & 7.0043 & $C_{\mathrm{D}_{\alpha=0}}$ & 0.0192 & 0.0252 & -23.8465 \\
\hline & $C_{\mathrm{L}_{\alpha=0}}$ & 0.4834 & 0.4784 & 1.031 & $C_{\mathrm{D}_{0}}$ & 0.009 & 0.0147 & -38.7264 \\
\hline \multirow[t]{2}{*}{3} & $C_{\mathrm{L}_{\alpha}}$ & 0.0840 & 0.084 & -0.0427 & $C_{\mathrm{D}_{\alpha=0}}$ & 0.0199 & 0.0277 & -28.2439 \\
\hline & $C_{\mathrm{L}_{\alpha=0}}$ & 0.4942 & 0.5116 & -3.3968 & $C_{\mathrm{D}_{0}}$ & 0.0092 & 0.0147 & -37.3399 \\
\hline \multirow[t]{2}{*}{4} & $C_{\mathrm{L}_{\alpha}}$ & 0.0866 & 0.0887 & -2.4246 & $C_{\mathrm{D}_{\alpha=0}}$ & 0.0209 & 0.0299 & -30.1275 \\
\hline & $C_{\mathrm{L}_{\alpha=0}}$ & 0.5140 & 0.5356 & -4.0341 & $C_{\mathrm{D}_{0}}$ & 0.0094 & 0.0147 & -36.0162 \\
\hline \multirow[t]{2}{*}{5} & $C_{\mathrm{L}_{\alpha}}$ & 0.0948 & 0.0931 & 1.8245 & $C_{\mathrm{D}_{\alpha=0}}$ & 0.0228 & 0.0316 & -27.8215 \\
\hline & $C_{\mathrm{L}_{\alpha=0}}$ & 0.5446 & 0.5498 & -0.9405 & $C_{\mathrm{D}_{0}}$ & 0.0099 & 0.0147 & -32.6322 \\
\hline
\end{tabular}

Fig. 17 HTP result comparison between RANS and $\mathrm{CA}^{2} \mathrm{LM}$

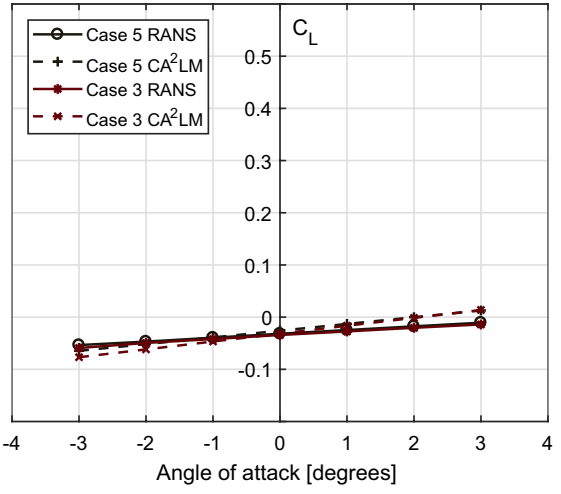

(a)

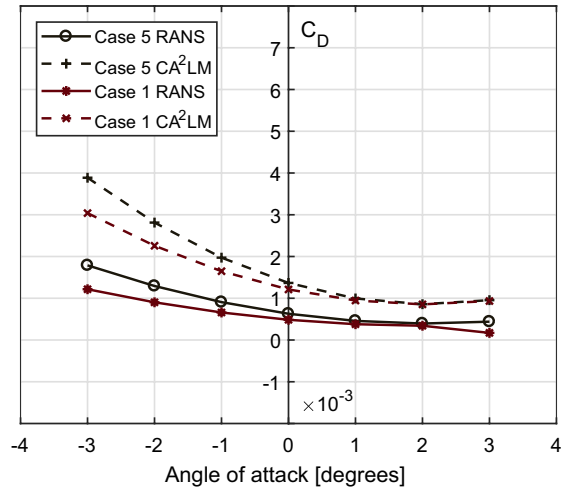

(b) 
Table 7 HTP lift and drag coefficient comparison for cases

\begin{tabular}{|c|c|c|c|c|c|c|c|c|}
\hline \multirow[t]{2}{*}{ Case } & & \multicolumn{3}{|l|}{ Lift } & & \multicolumn{3}{|l|}{ Drag } \\
\hline & & RANS & $\mathrm{CA}^{2} \mathrm{LM}$ & $\Delta_{\mathrm{L}}(\%)$ & & RANS & $\mathrm{CA}^{2} \mathrm{LM}$ & $\Delta_{\mathrm{D}}(\%)$ \\
\hline \multirow[t]{2}{*}{1} & $C_{\mathrm{L}_{\alpha}}$ & 0.0071 & 0.0129 & -45.0071 & $C_{\mathrm{D}_{\alpha=0}}$ & 0.0005 & 0.0012 & -60 \\
\hline & $C_{\mathrm{L}_{\alpha=0}}$ & -0.0312 & -0.0265 & 17.708 & $C_{\mathrm{D}_{0}}$ & 0.0004 & 0.0012 & -62.5511 \\
\hline \multirow[t]{2}{*}{2} & $C_{\mathrm{L}_{\alpha}}$ & 0.0072 & 0.0129 & -44.4552 & $C_{\mathrm{D}_{\alpha=0}}$ & 0.0006 & 0.0012 & -50 \\
\hline & $C_{\mathrm{L}_{\alpha=0}}$ & -0.0318 & -0.026 & 22.4126 & $C_{\mathrm{D}_{0}}$ & 0.0005 & 0.0012 & -53.5806 \\
\hline \multirow[t]{2}{*}{3} & $C_{\mathrm{L}_{\alpha}}$ & 0.0071 & 0.0137 & -48.5136 & $C_{\mathrm{D}_{\alpha=0}}$ & 0.0006 & 0.0012 & -50 \\
\hline & $C_{\mathrm{L}_{\alpha=0}}$ & -0.032 & -0.0276 & 16.0498 & $C_{\mathrm{D}_{0}}$ & 0.0006 & 0.0012 & -50.9433 \\
\hline \multirow[t]{2}{*}{4} & $C_{\mathrm{L}_{\alpha}}$ & 0.0072 & 0.0144 & -50.2011 & $C_{\mathrm{D}_{\alpha=0}}$ & 0.0006 & 0.0013 & -50 \\
\hline & $C_{\mathrm{L}_{\alpha=0}}$ & -0.0328 & -0.0289 & 13.2377 & $C_{\mathrm{D}_{0}}$ & 0.0006 & 0.0012 & -49.4118 \\
\hline \multirow[t]{2}{*}{5} & $C_{\mathrm{L}_{\alpha}}$ & 0.0075 & 0.0151 & -50.1655 & $C_{\mathrm{D}_{\alpha=0}}$ & 0.0006 & 0.0014 & -54 \\
\hline & $C_{\mathrm{L}_{\alpha=0}}$ & -0.0343 & -0.0316 & 8.3293 & $C_{\mathrm{D}_{0}}$ & 0.0006 & 0.0012 & -51.0521 \\
\hline
\end{tabular}

be noted that although the HTP aerofoil section is symmetric, the drag polars for both methods are not because of the induced angle of attack from the wing downwash. Furthermore, the simplified approach to downwash modeling in $\mathrm{CA}^{2} \mathrm{LM}$ results in a significant overestimation of HTP drag. As for the differences in $C_{\mathrm{D}_{0}}$, Table 7 shows that these are between $32 \%$ and $40 \%$. These differences can be attributed on how $\mathrm{CA}^{2} \mathrm{LM}$ calculates the downwash.

Finally, the vertical tailplane (VTP) is analyzed to see its interaction with the fuselage. As stated previously, $\mathrm{CA}^{2} \mathrm{LM}$ lacks this specific interaction. It is expected that such an interaction will increase the overall drag count of the aircraft. Moreover, here, the $C_{\mathrm{L}}$ analysis is not considered for the VTP, because the primary force vector (lift) is perpendicular to the flow and contributes primarily through a sideforce which leads to a yawing moment. Only the $C_{\mathrm{D}}$ comparison is made.

Looking into the results, Fig. 18 shows that $\mathrm{CA}^{2} \mathrm{LM}$ outputs have the same values regardless of the change in angle of attack. This implies that the reduce order model does not apply any drag change with angle of attack. The difference between $\mathrm{CA}^{2} \mathrm{LM}$ and RANS varies from almost $49 \%$ to $67 \%$ and is presented in Table 8 .

\section{Lift and drag coefficient comparison between cases 6 and 7}

The comparisons made between $\mathrm{CA}^{2} \mathrm{LM}$ and RANS for cases 1-5 provide some insight into differences as flight conditions are changed. As $\mathrm{CA}^{2} \mathrm{LM}$ was designed as a tool for flight load prediction and analysis, the effects of wing deformation need to be considered. A comparison of results obtained from cases 6 (undeformed) and 7 (deformed) allows the impact of changes in wing geometry due to flight loads on aerodynamic properties to be studied. Again, the relative differences for lift and drag coefficients are used for comparing results. In this analysis, the

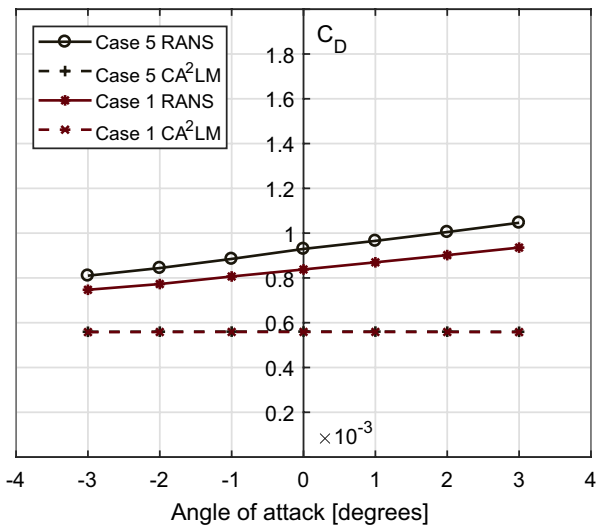

Fig. 18 VTP result comparison between RANS and $\mathrm{CA}^{2} \mathrm{LM}$ for $C_{\mathrm{D}}$

Table 8 VTP drag coefficient comparison for cases $1-5$

\begin{tabular}{lllll}
\hline Case & & & \\
\cline { 3 - 5 } & & RANS & $\mathrm{CA}^{2} \mathrm{LM}$ & $\Delta_{\mathrm{D}}(\%)$ \\
\hline 1 & $C_{\mathrm{D}_{\alpha=0}}$ & $8.378 \mathrm{e}^{-04}$ & $5.588 \mathrm{e}^{-04}$ & 49.930 \\
& $C_{\mathrm{D}_{0}}$ & $8.378 \mathrm{e}^{-04}$ & $5.588 \mathrm{e}^{-04}$ & 49.928 \\
\multirow{2}{*}{3} & $C_{\mathrm{D}_{\alpha=0}}$ & $8.416 \mathrm{e}^{-04}$ & $5.447 \mathrm{e}^{-04}$ & 54.493 \\
& $C_{\mathrm{D}_{0}}$ & $8.416 \mathrm{e}^{-04}$ & $5.588 \mathrm{e}^{-04}$ & 50.606 \\
& $C_{\mathrm{D}_{\alpha=0}}$ & $8.712 \mathrm{e}^{-04}$ & $5.643 \mathrm{e}^{-04}$ & 54.378 \\
& $C_{\mathrm{D}_{0}}$ & $8.711 \mathrm{e}^{-04}$ & $5.588 \mathrm{e}^{-04}$ & 55.900 \\
& $C_{\mathrm{D}_{\alpha=0}}$ & $9.043 \mathrm{e}^{-04}$ & $5.663 \mathrm{e}^{-04}$ & 59.672 \\
& $C_{\mathrm{D}_{0}}$ & $9.043 \mathrm{e}^{-04}$ & $5.588 \mathrm{e}^{-04}$ & 61.829 \\
& $C_{\mathrm{D}_{\alpha=0}}$ & $9.295 \mathrm{e}^{-04}$ & $5.603 \mathrm{e}^{-04}$ & 65.883 \\
& $C_{\mathrm{D}_{0}}$ & $9.295 \mathrm{e}^{-04}$ & $5.588 \mathrm{e}^{-04}$ & 66.344 \\
\hline
\end{tabular}

terms $\Delta_{\mathrm{L}_{\mathrm{g}}}$ and $\Delta_{\mathrm{D}_{\mathrm{g}}}$ are introduced to evaluate the relative differences due to the geometric changes of the wing:

$\Delta_{\mathrm{L}_{\mathrm{g}}}=\frac{\dot{C}_{[]}-\ddot{C}_{[]}}{\ddot{C}_{[]}}$, 
$\Delta_{\mathrm{D}_{g}}=\frac{\dot{C}_{\mathrm{D}_{0}}-\ddot{C}_{\mathrm{D}_{0}}}{\ddot{C}_{\mathrm{D}_{0}}}$.

Here, $\dot{C}$ represent the data of case 7 and $\ddot{C}$ the data from case 6.

\subsection{Lift and drag comparison for the entire aircraft}

Considering the data in Fig. 19a, it can be seen that both RANS and $C^{2}{ }^{2} L M$ give very similar results for both the deformed and undeformed cases. In both cases, the difference in $\Delta_{\mathrm{L}_{\alpha}}$ and $\Delta_{\mathrm{L}_{0}}$ are approximately $7 \%$ and $12 \%$, respectively. This shows that both $\mathrm{CA}^{2} \mathrm{LM}$ and RANS results maintain sufficient agreement in the case of deformed wing shape. As for the difference due to the structural flexibility effects, $\Delta_{\mathrm{L}_{\mathrm{g}}}$ is also fairly similar. $\Delta_{\mathrm{L}_{\mathrm{g}_{\alpha}}}$ is approximately $1 \%$ in both methods, while $\Delta_{\mathrm{L}_{0}}$ reaches $20 \%$ and $25 \%$ in the RANS and $C^{2}$ LM results, respectively (as shown in Table 9). This indicates a slight overestimation in $\mathrm{CA}^{2} \mathrm{LM}$ when predicting changes in $C_{\mathrm{L}}$ due to wing flexibility.

Figure $19 \mathrm{~b}$ and Table 9 gather the $C_{\mathrm{D}}$ results for the same comparison. Whilst $\Delta_{\mathrm{D}}$ for case 6 is $14.8 \%, \Delta_{\mathrm{D}}$ for case 7 is smaller with a $10.9 \%$. This suggests a greater agreement of both methods in the deformed shape. It is also shown that, once again, changes to aerodynamic coefficients are greater in $\mathrm{CA}^{2} \mathrm{LM}$ than in RANS results, with a better agreement in the case of $C_{\mathrm{D}}$ than the previously discussed $C_{\mathrm{L}}$.

\subsection{Wing lift and drag coefficient comparison}

Looking in more detail to the performance losses due to the deformed shape of the wing, Table 10 shows that the difference between the two solvers is less than $10 \%$. For the undeformed configuration, $\mathrm{CA}^{2} \mathrm{LM}$ overestimates the results, but in the deformed configuration, the opposite occurs: a slight underestimation in the lift produced by the wing is presented in Fig. 20a. As for the loss in lift coefficient due to the geometry change, the difference in RANS and $\mathrm{CA}^{2} \mathrm{LM}$ is more or less similar with around $30 \%$, with a relative difference of $4 \%$ between the two methods.

The drag coefficient on the other hand does not follow the same trends as evident in Fig. 20b. At low angles of attack all cases have a relatively small difference which increases with the angle of attack. Case 6 shows a $36.9 \%$ difference, whilst case 7 is at $32.8 \%$, as shown in Table 10 . Once again, $\mathrm{CA}^{2} \mathrm{LM}$ tends to overestimate the drag when compared to RANS, but with a better convergence in the deformed configuration. Geometry changes seem to have a larger impact for $\mathrm{CA}^{2} \mathrm{LM}$ than RANS with changes at $29 \%$ and $19 \%$, respectively.

\subsection{Horizontal tailplane lift and drag coefficient comparison}

The HTP is analyzed to capture the impact of wing deformation on the flow hitting the tail of the aircraft
Fig. 19 Comparison of overall airframe aerodynamics
Table 9 Aircraft lift $\left(C_{\mathrm{L}_{\alpha}}\right.$ and $\left.C_{\mathrm{L}_{\alpha=0}}\right)$ and drag $\left(C_{\mathrm{D}_{\alpha=0}}\right)$ coefficient comparison for cases 6 and 7

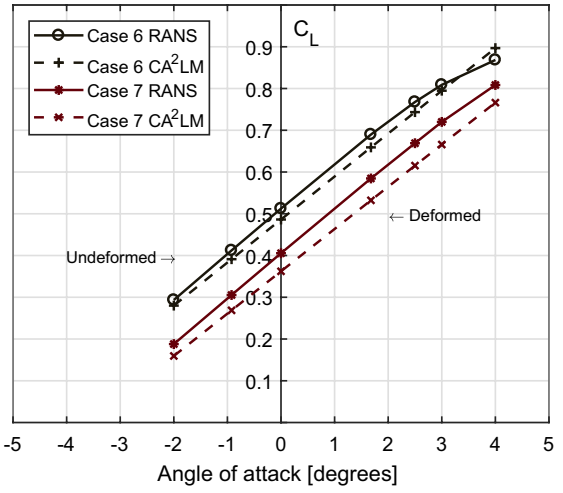

(a)

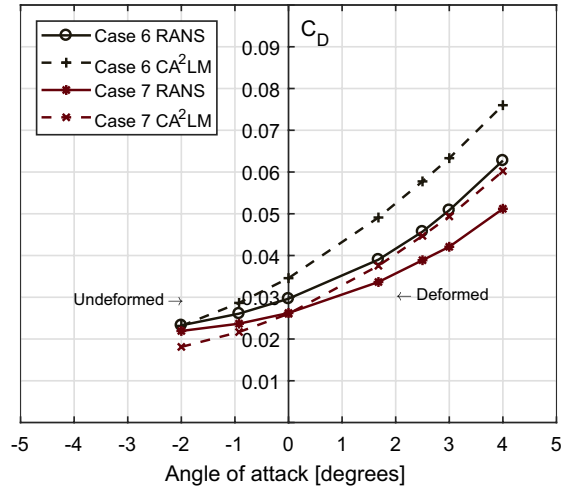

(b)

\begin{tabular}{|c|c|c|c|c|c|c|c|c|}
\hline \multirow[t]{2}{*}{ Case } & & \multicolumn{3}{|l|}{ Lift } & & \multicolumn{3}{|l|}{ Drag } \\
\hline & & RANS & $\mathrm{CA}^{2} \mathrm{LM}$ & $\Delta_{\mathrm{L}}(\%)$ & & RANS & $\mathrm{CA}^{2} \mathrm{LM}$ & $\Delta_{\mathrm{D}}(\%)$ \\
\hline \multirow[t]{2}{*}{6} & $C_{\mathrm{L}_{\alpha}}$ & 0.1095 & 0.1031 & 6.1612 & $C_{\mathrm{D}_{\alpha=0}}$ & 0.0297 & 0.0346 & -14.2356 \\
\hline & $C_{\mathrm{L}_{\alpha=0}}$ & 0.5124 & 0.4863 & 5.3747 & $C_{\mathrm{D}_{0}}$ & 0.0182 & 0.0214 & -14.8261 \\
\hline \multirow[t]{2}{*}{7} & $C_{\mathrm{L}_{\alpha}}$ & 0.1088 & 0.1014 & 7.3027 & $C_{\mathrm{D}_{\alpha=0}}$ & 0.0262 & 0.026 & 0.7394 \\
\hline & $C_{\mathrm{L}_{\alpha=0}}$ & 0.4055 & 0.3622 & 11.9556 & $C_{\mathrm{D}_{0}}$ & 0.0191 & 0.0214 & -10.9065 \\
\hline \multirow[t]{2}{*}{$\Delta_{\mathrm{G}}$} & $\Delta_{\mathrm{L}_{\alpha}}$ & -0.6309 & -1.688 & & $\Delta_{\mathrm{D}_{\alpha=0}}$ & -11.56 & -24.7066 & \\
\hline & $\Delta_{\mathrm{L}_{\alpha=0}}$ & -20.8638 & -25.5156 & & $\Delta_{\mathrm{D}_{0}}$ & 4.6019 & 0 & \\
\hline
\end{tabular}


(downwash). Figure 21a presents an interesting effect in which the deformed geometry in both solvers produce less downforce than the undeformed configuration, as shown in Table 11. $C_{\mathrm{L}_{\alpha=0}}$ differences for both cases between $\mathrm{CA}^{2} \mathrm{LM}$ and RANS are around $11.5 \%$. As for $C_{\mathrm{L}_{\alpha}}$, there is a significant difference of $44 \%$ in case 6 and $48 \%$ in case 7 where the lift curve slope predicted by $\mathrm{CA}^{2} \mathrm{LM}$ is significantly higher for both deformed and undeformed cases. When looking into lift generated by the wing geometry change, case 7 produces less downforce than case 6 , although these are at the same flight condition. This is also evident in the differences between each of the cases: RANS simulations have a difference of around $40 \%$, whereas $\mathrm{CA}^{2} \mathrm{LM}$ shows a $53 \%$ difference.

Figure $21 \mathrm{~b}$ and Table 11 summarize the findings for $C_{\mathrm{D}}$. As expected, $\mathrm{CA}^{2} \mathrm{LM}$ overestimates the drag produced when compared to RANS. Case 6 has a difference of $35.59 \%$ and case 7 around $57.67 \%$. It should be noted that in $\mathrm{CA}^{2} \mathrm{LM}$, the undeformed configuration produces more drag than the deformed at angles of attack below $2^{\circ}$. All these differences can be attributed to the change in the downwash produced by wing deformation.
Fig. 20 Comparison of wing aerodynamics

Table 10 Wing lift and drag coefficient comparison for cases 6 and 7

Fig. 21 Comparison of HTP aerodynamics

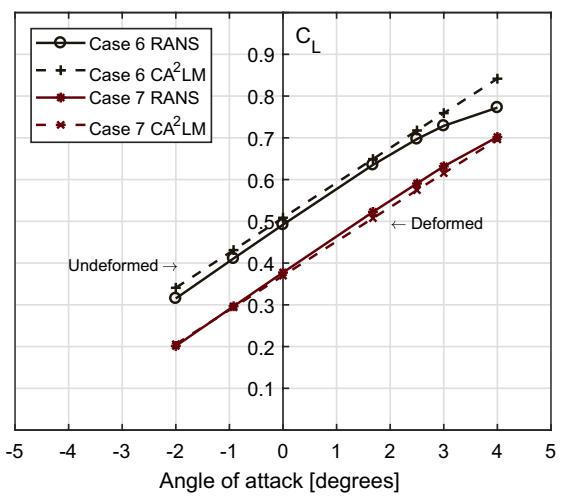

(a)

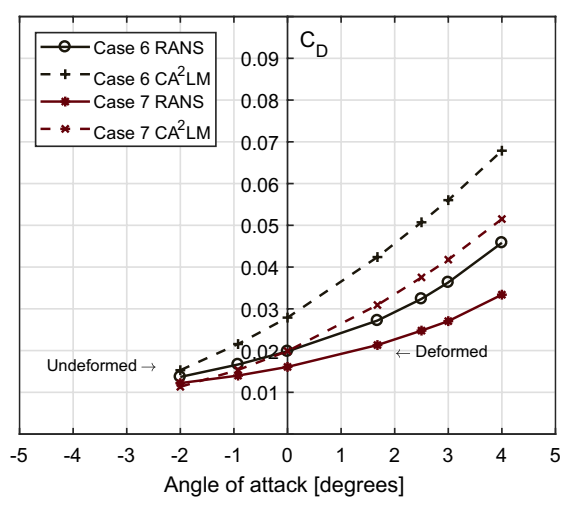

(b)

\begin{tabular}{|c|c|c|c|c|c|c|c|c|}
\hline \multirow[t]{2}{*}{ Case } & & \multicolumn{3}{|l|}{ Lift } & & \multicolumn{3}{|l|}{ Drag } \\
\hline & & RANS & $\mathrm{CA}^{2} \mathrm{LM}$ & $\Delta_{\mathrm{L}}(\%)$ & & RANS & $\mathrm{CA}^{2} \mathrm{LM}$ & $\Delta_{\mathrm{D}}(\%)$ \\
\hline \multirow[t]{2}{*}{6} & $C_{\mathrm{L}_{\alpha}}$ & 0.0884 & 0.0839 & 5.348 & $C_{\mathrm{D}_{\alpha=0}}$ & 0.0198 & 0.0279 & -28.9726 \\
\hline & $C_{\mathrm{L}_{\alpha=0}}$ & 0.492 & 0.5086 & -3.2591 & $C_{\mathrm{D}_{0}}$ & 0.0093 & 0.0147 & -36.9415 \\
\hline \multirow[t]{2}{*}{7} & $C_{\mathrm{L}_{\alpha}}$ & 0.088 & 0.0821 & 7.076 & $C_{\mathrm{D}_{\alpha=0}}$ & 0.0161 & 0.0199 & -19.0414 \\
\hline & $C_{\mathrm{L}_{\alpha=0}}$ & 0.3774 & 0.3699 & 2.0182 & $C_{\mathrm{D}_{0}}$ & 0.0099 & 0.0147 & -32.8137 \\
\hline \multirow[t]{2}{*}{$\Delta_{\mathrm{G}}$} & $\Delta_{\mathrm{L}_{\alpha}}$ & -0.4848 & -2.0909 & & $\Delta_{\mathrm{D}_{\alpha=0}}$ & -18.8109 & -28.7704 & \\
\hline & $\Delta_{\mathrm{L}_{\alpha=0}}$ & -23.3025 & -27.27 & & $\Delta_{\mathrm{D}_{0}}$ & 6.5461 & 0 & \\
\hline
\end{tabular}

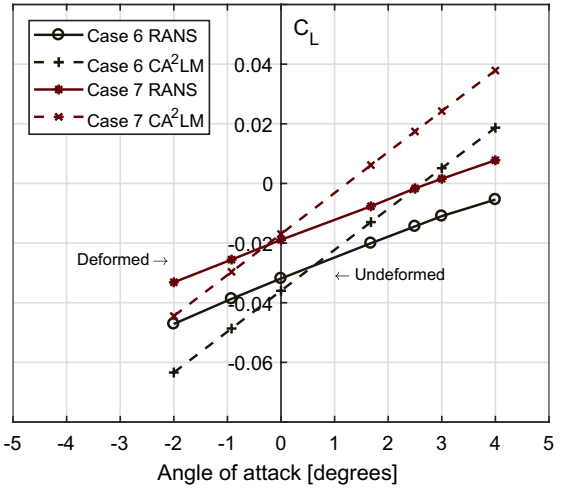

(a)

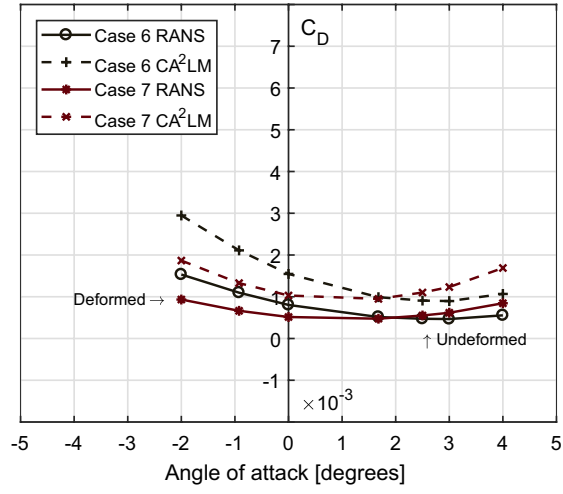

(b) 
Table 11 HPT lift $\left(C_{\mathrm{L}_{\alpha}}\right.$ and $\left.C_{\mathrm{L}_{\alpha=0}}\right)$ and $\operatorname{drag}\left(C_{\mathrm{D}_{\alpha=0}}\right)$ coefficient comparison for cases 6 and 7

\begin{tabular}{|c|c|c|c|c|c|c|c|c|}
\hline \multirow[t]{2}{*}{ Case } & & \multicolumn{3}{|l|}{ Lift } & & \multicolumn{3}{|l|}{ Drag } \\
\hline & & RANS & $\mathrm{CA}^{2} \mathrm{LM}$ & $\Delta_{\mathrm{L}}(\%)$ & & RANS & $\mathrm{CA}^{2} \mathrm{LM}$ & $\Delta_{\mathrm{D}}(\%)$ \\
\hline \multirow[t]{2}{*}{6} & $C_{\mathrm{L}_{\alpha}}$ & 0.0076 & 0.0137 & -44.382 & $C_{\mathrm{D}_{\alpha=0}}$ & 0.0008 & 0.0015 & -48 \\
\hline & $C_{\mathrm{L}_{\alpha=0}}$ & -0.0319 & -0.036 & -11.425 & $C_{\mathrm{D}_{0}}$ & 0.0008 & 0.0012 & -35.5975 \\
\hline \multirow[t]{2}{*}{7} & $C_{\mathrm{L}_{\alpha}}$ & 0.0071 & 0.0138 & -48.229 & $C_{\mathrm{D}_{\alpha=0}}$ & 0.0005 & 0.001 & -50 \\
\hline & $C_{\mathrm{L}_{\alpha=0}}$ & -0.0189 & -0.017 & 11.5049 & $C_{\mathrm{D}_{0}}$ & 0.0005 & 0.0012 & -57.6724 \\
\hline \multirow[t]{2}{*}{$\Delta_{\mathrm{G}}$} & $\Delta_{\mathrm{L}_{\alpha}}$ & -6.5959 & 0.3447 & & $\Delta_{\mathrm{D}_{\alpha=0}}$ & -35.9545 & -33.3927 & \\
\hline & $\Delta_{\mathrm{L}_{\alpha=0}}$ & -40.6782 & -52.8771 & & $\Delta_{\mathrm{D}_{0}}$ & -34.2764 & 0 & \\
\hline
\end{tabular}

\section{Conclusions}

This study was conducted to verify the accuracy of reduced order aerodynamic models used in $\mathrm{CA}^{2} \mathrm{LM}$ - an aeroservoelastic framework used for flight loads analysis at the very early aircraft design stages. This was done by comparing the output of the various aerodynamic modules in $\mathrm{CA}^{2} \mathrm{LM}$ with results obtained from Reynolds Averaged Navier-Stokes simulations. The main motivation behind this work was to understand the suitability of the numerous reduced order aerodynamic modeling methods which have been coupled with empirical models within $\mathrm{CA}^{2} \mathrm{LM}$. The use case for this study was the $\mathrm{AX}-1$ aircraft configuration that represents a conventional large civil transport aircraft. As stated before the aim of this work is to highlight the limitations of a specific modeling approach that couples MST-based steady aerodynamic models with ESDU methods. This verification focused on two steady aerodynamic modeling aspects: (1) a comparison over a range of flight conditions and (2) assessing the effects of wing deformation. For each, the overall lift and drag coefficients are compared together with the aerodynamic contributions from individual aircraft components.

The key finding of this study was that the overall aircraft lift and drag modeling within $\mathrm{CA}^{2} \mathrm{LM}$ produces results in satisfactory agreement with the RANS simulations. However, this agreement was found to be a consequence of numerous underestimations and overestimations at the component levels. Overall drag estimation in $\mathrm{CA}^{2} \mathrm{LM}$ was found to be too conservative and mainly driven by the limitations of the MST approach used to model the various aerodynamic surfaces. Lift and drag contributions from the empirical fuselage model were found to be grossly underestimated. Comparing the results for the cases where the wing was deformed and left undeformed, the expected reduced lift coefficient due to the reduction in effective wingspan was found. However, in all cases, the primary driver behind the differences observed for the horizontal tailplane was found to be the simplified wing downwash model implemented in $\mathrm{CA}^{2} \mathrm{LM}$. This not only affects the accuracy of aerodynamic performance, but also has a significant impact on flight dynamic modeling where delays due to wing-tailplane interactions determine critical flight loads.
To understand the root cause of the discrepancy and to compensate for these differences, a more in-depth study focusing on analysing the lift and moment distributions along the span of the lifting surfaces, the way which the $\mathrm{CA}^{2} \mathrm{LM}$ calculate the fuselage aerodynamic characteristics and the way which the downwash is calculated for the HTP are needed and form the basis of future research.

Acknowledgements The authors would like to thank the National Council of Science and Technology (CONACYT) (Grant no. 459126) of Mexico and Cranfield University for all its support.

Open Access This article is distributed under the terms of the Creative Commons Attribution 4.0 International License (http://creativeco mmons.org/licenses/by/4.0/), which permits unrestricted use, distribution, and reproduction in any medium, provided you give appropriate credit to the original author(s) and the source, provide a link to the Creative Commons license, and indicate if changes were made.

\section{References}

1. Anderson, J.: Computational fluid dynamics, 1st edn. McGrawHill, New York (1995)

2. Andrews, S., Cooke, A.: An aeroelastic flexible wing model for aircraft simulation. In: 48th AIAA Aerospace Sciences Meeting Including the New Horizons Forum and Aerospace Exposition (Jan) (2010). https://doi.org/10.2514/6.2010-35

3. Andrews, S.P.: Modelling and simulation of flexible aircraft: handling qualities with active load control. Ph.D. thesis, Cranfield University, Cranfield, UK (2011)

4. Cook, M.V.: Flight Dynamics Principles: A Linear Systems Approach to Aircraft Stability and Control, 3rd edn. Elsevier Aerospace Engineering Series. Butterworth-Heinemann, Amsterdam (2013)

5. Deyoung, J., Harper, C.W.: Theoretical Symmetric Span Loading at Subsonic Speeds for Wings Having Arbitrary Plan Form. Technical Report 19930091985, National Advisory Committee for Aeronautics, Moffett Field, CA (1948)

6. Dreier, M.E.: Introduction to Helicopter and Tiltrotor Flight Simulation. American Institute of Aeronautics and Astronautics, Arlimgton (2007). https://doi.org/10.2514/4.862083

7. Drela, M., Giles, M.B.: Viscous-inviscid analysis of transonic and low Reynolds number airfoils. AIAA J. 25(10), 1347-1355 (1987). https://doi.org/10.2514/3.9789

8. Lone, M., Dussart, G.: Impact of spanwise non-uniform discrete gusts on civil aircraft loads. Aeronaut. J. 123(1259), 93-120 (2019). https://doi.org/10.1017/aer.2018.148 
9. ESDU: Normal-force-curve and pitching-moment-curve slopes of forebody-cylinder combinations at zero angle of attack for Mach numbers up to 5. Technical Report ESDU 89008 (1990)

10. ESDU: Normal force and pitching moment of conical boat-tails. Technical Report ESDU 87033 (1992)

11. ESDU: Symmetric steady manoeuvre loads on rigid aircraft of classical configuration at subsonic speeds. Technical Report ESDU 94009 (1994)

12. ESDU: Lift-curve slope of wing-body combinations. Technical Report December, IHS ESDU (1995)

13. ESDU: Normal force, pitching moment and side force of forebody-cylinder combinations for angles of attack up to 90 degrees and Mach numbers up to 5. Technical Report ESDU 89014 (2004)

14. ESDU: VGK method for two-dimensional aerofoil sections. Technical Report April, IHS ESDU (2004)

15. ESDU: Geometrical properties of cranked and straight-tapered wing planforms. Technical Report May, IHS ESDU (2012)

16. ESDU: Aerodynamic centre of wing-fuselage-nacelle combinations: effect of wing-pylon mounted nacelles. Technical Report ESDU 77012 (2013)

17. ESDU: Geometrical characteristics of typical bodies. Technical Report July, IHS ESDU (2017)

18. Fujiwara, G.E., Bragg, M.B.: 3D Computational icing method for aircraft conceptual design. In: 9th AIAA Atmospheric and Space Environments Conference, June, p. 29 (2017). https://doi. org/10.2514/6.2017-4375

19. Gallay, S., Ghasemi, S., Laurendeau, E.: Sweep effects on non-linear lifting line theory near stall. In: 52nd Aerospace Sciences Meeting, January, pp. 1-19 (2014). https://doi. org/10.2514/6.2014-1105

20. Ghoreyshi, M., Frink, N.T., van Rooij, M., Lofthouse, A.J., Cummings, R.M., Nayani, S.: Collaborative evaluation of CFD-toROM dynamic modeling. In: 54th AIAA Aerospace Sciences Meeting, AIAA SciTech Forum, January, pp. 1-27. San Diego, CA (2016). https://doi.org/10.2514/6.2016-1077

21. Howe, D.: Aircraft conceptual design synthesis. Professional Engineering Publishing Limited, Bury St Edmunds (2000). https ://doi.org/10.1002/9781118352700

22. Karman, T.V.: Mechanical similitude and turbulence. Technical Report 19930094805, National Advisory Committee for Aeronautics, Washington (1930)

23. Kato, M., Launder, B.: The modeling of turbulent flow around stationary and vibrating square cylinders. In: Ninth Symposium on Turbulent Shear Flows, pp. 10.4.1-10.4.6. Springer, Kyoto (1993). https://doi.org/10.1007/s13398-014-0173-7.2

24. Langtry, R.B.: Correlation-based transition modeling for unstructured parallelized computational fluid dynamics codes. AIAA J. 47(12), 2894-2906 (2009). https://doi.org/10.2514/1.42362

25. Launder, B.E., Spalding, D.B.: The numerical computation of turbulent flows. Comput. Methods Appl. Mech. Eng. 3, 269-289 (1974). https://doi.org/10.1016/0045-7825(74)90029-2

26. Leishman, J.G.: Unsteady lift of a flapped airfoil by indicial concepts. J. Aircr. 31(2), 288-297 (1994). https://doi. org/10.2514/3.46486

27. Leishman, J.G., Nguyen, K.Q.: State-space representation of unsteady airfoil behavior. AIAA J. 28(5), 836-844 (1990). https ://doi.org/10.2514/3.25127

28. Lone, M.M, Cooke, A.: Review of Pilot Modelling Techniques. In: 48th AIAA Aerospace Sciences Meeting Including the New Horizons Forum and Aerospace Exposition. American Institute of Aeronautics and Astronautics, Orlando, FL (2010). https://doi. org/10.2514/6.2010-297

29. Lone, M.M., Cooke, A.K.: Pilot-model-in-the-loop simulation environment to study large aircraft dynamics. J. Aerosp. Eng. 227(3), 555-568 (2012). https://doi.org/10.1177/0954410011 434342
30. Lone, M.M., Lai, C.K., Cooke, A., Whidborne, J.F.: Framework for flight loads analysis of trajectory-based manoeuvres with pilot models. J. Aircr. 51(2), 637-650 (2014). https://doi.org/10.2514/1. C032376

31. Palacios, R., Cesnik, C.E.S.: Low-speed aeroelastic modeling of very flexible slender wings with deformable airfoils. In: 49th Structural Dynamics and Materials Conference, pp. 1-19. American Institute of Aeronautics and Astronautics, Schaumburg, IL (2008). https://doi.org/10.2514/6.2008-1995

32. Palacios, R., Murua, J., Cook, R.: Structural and aerodynamic models in nonlinear flight dynamics of very flexible aircraft. AIAA J. 48(11), 2648-2659 (2010). https://doi.org/10.2514/1.J050513

33. Patil, M.J., Hodges, D.H., Cesnik, C.E.S.: Nonlinear aeroelasticity and flight dynamics of high-altitude long-endurance aircraft. J. Aircr. 38(1), 88-94 (2001). https://doi.org/10.2514/2.2738

34. Portapas, V., Cooke, A., Lone, M.: Modelling framework for flight dynamics of flexible aircraft. Aviation 20(4), 173-182 (2016). https://doi.org/10.3846/16487788.2016.1264719

35. Salim, S.M., Ariff, M., Cheah, S.C.: Wall y+ approach for dealing with turbulent flows over a wall mounted cube. Prog. Comput. Fluid Dyn. (2010). https://doi.org/10.1504/PCFD.2010.035368

36. Salim, S.M., Cheah, S.: Wall y+ strategy for dealing with wallbouded turbulent flows. In: International MultiConference of Engineers and Computer Scientists, pp. 1-6. IMECS, Hong Kong, China (2009)

37. Schütte, A., Einarsson, G., Raichle, A., Schöning, B., Mönnich, W., Orlt, M., Neumann, J., Arnold, J., Forkert, T.: Numerical simulation of maneuvering aircraft by aerodynamic, flight mechanics and structural mechanics coupling. J. Aircr. 46(1), 53-64 (2009). https://doi.org/10.2514/1.31182

38. Spalart, P.R., Allmaras, S.R., Allmaras, S.R.: A one-equatlon turbulence model for aerodynamic flows. In: 30th Aerospace Sciences Meeting and Exhibit, Aerospace Sciences Meetings, pp. 1-22. AIAA, Reno, NV (1992). https://doi. org/10.2514/6.1992-439

39. Valente, C., Jones, D., Gaitonde, A., Cooper, J.E., Lemmens, Y.: Doublet-lattice method correction by means of linearised frequency domain solver analysis. In: 15th Dynamics Specialists Conference, pp. 1-14. American Institute of Aeronautics and Astronautics, San Diego, CA (2016). https://doi. org/10.2514/6.2016-1575

40. Van Dam, C.P.: The aerodynamic design of multi-element high-lift systems for transport airplanes. Prog. Aerosp. Sci. 38(2), 101-144 (2002). https://doi.org/10.1016/S0376-0421(02)00002-7

41. Waszak, M.R., Schmidt, D.K.: Flight dynamics of aeroelastic vehicles. J. Aircr. 25(6), 563-571 (1988). https://doi. org/10.2514/3.45623

42. Weissinger, J.: The lift distribution of swept-back wings. Technical Report 20030064148, National Advisory Committee for Aeronautics, Washington, D.C. (1947)

43. Wilcox, D.C.: Reassessment of the scale-determining equation for advanced turbulence models. AIAA J. 26(11), 1299-1310 (1988). https://doi.org/10.2514/3.10041

44. Wilcox, D.C.: Turbulence Modeling for CFD, 3rd edn. DWC Industries, La Cañada (2006)

45. Willcox, K., Wakayama, S.: Simultaneous optimization of a multiple-aircraft family. J. Aircr. 40(4), 616-622 (2003). https://doi. org/10.2514/2.3156

Publisher's Note Springer Nature remains neutral with regard to jurisdictional claims in published maps and institutional affiliations. 